\title{
Adapting the Sudden Landslide Identification Product (SLIP) and Detecting Real-Time Increased Precipitation (DRIP) algorithms to map rainfall- triggered landslides in the West-Cameroon highlands (Central-Africa)
}

ALFRED HOMERE NGANDAM MFONDOUM ( $\square$ ngandamh@yahoo.com )

Universite de Yaounde I https://orcid.org/0000-0001-5917-1275

Pauline Wokwenmendam Nguet

Institute of Mining and Geological Research

Jean Valery Mefire Mfondoum

Universite Toulouse 1 Capitole Toulouse School of Economics

Mesmin Tchindjang

Universite de Yaounde I

\section{Sofia Hakdaoui}

Universite Mohammed V de Rabat Faculte des Sciences

Ryan Cooper

University of Texas at Dallas Erik Jonsson School of Engineering and Computer Science

Paul Gérard Gbetkom

Aix-Marseille Universite - Campus Aix-en-Provence Schuman

Joseph Penaye

Institute of Mining and Geological Research

Ateba Bekoa

Institute of Mining and geological Research

Cyriel Moudioh

Institute of Mining and Geological Research

\section{Methodology}

Keywords: SLIP, DRIP, real-time mapping, geohazard, West-Cameroons' Highlands, rainfall-triggered Landslides, Cox model, LHZ

Posted Date: February 1st, 2021

DOI: https://doi.org/10.21203/rs.3.rs-19292/v4 
License: (c) (i) This work is licensed under a Creative Commons Attribution 4.0 International License. Read Full License

Version of Record: A version of this preprint was published at Geoenvironmental Disasters on July 30th, 2021. See the published version at https://doi.org/10.1186/s40677-021-00189-9. 


\title{
Adapting the Sudden Landslide Identification Product (SLIP) and Detecting Real-Time Increased Precipitation (DRIP) algorithms to map rainfall-triggered landslides in the West- Cameroon highlands (Central-Africa)
}

\author{
Alfred Homère Ngandam Mfondoum*1,2, Pauline Wokwenmendam Nguet ${ }^{3}$, Jean Valery Mefire Mfondoum ${ }^{4}$, \\ Mesmin Tchindjang 2 , Sofia Hakdaoui ${ }^{5}$, Ryan Cooper $^{6}$, Paul Gérard Gbetkom ${ }^{7}$, Joseph Penaye ${ }^{3}$, Ateba Bekoa ${ }^{3}$, \\ Cyriel Moudioh ${ }^{3}$
}

\begin{abstract}
Background - NASA's developers recently proposed the Sudden Landslide Identification Product (SLIP) and Detecting Real-Time Increased Precipitation (DRIP) algorithms. This method uses the Landsat 8 satellite images and daily rainfall recordings for a real-time mapping of this geohazard. This study adapts the processing to face the issues of data quality and unavailability/gaps for the mapping of the recent landslide events in west-Cameroon's highlands.

Methods - The SLIP algorithm is adapted, by integrating the inverse NDVI to assess the soil bareness, the Modified Normalized Multi-Band Drought Index (MNMDI) combined with the hydrothermal index to assess soil moisture, and the slope inclination to map the recent landslide. Further, the DRIP algorithm uses the mean daily rainfall to assess the thresholds corresponding to the recent landslide events. Their probability density function (PDF) curves are superimposed and their intersections are used to propose sets of dichotomous variables before (1948-2018) and after the 28 October 2019 landslide event. In addition, a survival analysis is performed to correlate the occurrence date of the landslide with the rainfall since the first known event in Cameroon, through the Cox model.
\end{abstract}

Results - From the SLIP model, the Landslide Hazard Zonation (LHZ) map gives an overall accuracy of 96\%. Further, the DRIP model states that 6/9 ranges of probability are rainfall-triggered landslides at $99.99 \%$, between June and October, while $3 / 9$ ranges show only $4.88 \%$ of risk for the same interval. Finally, the survival probability for a known site is up to 0.68 for the best value and between 0.38 and 0.1 for the lowest value through time.

Conclusions - The proposed approach is an alternative based on data (un)availability, completed by the site's lifetime.

Keywords - SLIP, DRIP, real-time mapping, geohazard, West-Cameroons' Highlands, rainfall-triggered Landslides, Cox model, LHZ.

\footnotetext{
${ }^{1}$ StatsN'Maps, Private Consulting Firm, Dallas, Texas, USA.

*Correspondence: stats.n.maps.expertise@ gmail.com

2DDepartment of Geography, University of Yaoundé I, Cameroon. ngandamh@yahoo.com ; mtchind@yahoo.fr.

${ }^{3}$ Institute of Mining and Geological Research, PoBox 4110, Yaoundé, Cameroon. nguetpauline@ yahoo.fr.

${ }^{4}$ Department of Statistics and econometrics, University of Toulouse Capitol 1, France. valerymfondoum@gmail.com. ${ }^{5}$ Earth Observation department, Geo-Biodiversity and Natural Patrimony Laboratory, Geophysics, Natural Patrimony and Green Chemistry Research Center, Scientific Institute, Mohamed V University, Rabat, Morocco. s.hakdaoui@gmail.com.

${ }^{6}$ Erik Jonsson School of Engineering and Computer Science, University of Texas in Dallas, Texas 75080, USA. Rdc190001@utdallas.edu.

${ }^{7}$ Department of Geography, University of Aix-Marseille, France. ggbetkom@gmail.com.
} 


\section{Background}

Landslide refers to a sudden outward and downward gravitational mass wasting process of earth materials (rock, soils, artificial fill), triggered by variety of external factors or mechanisms (earthquakes, rainfall, reservoir impoundment, anthropogenic activities), but which do not require a transportation medium (water, air or ice) (Varnes, 1958, 1978 \&1984; Brusden, 1984; Crozier, 1986; Hutchinson, 1988; Cruden, 1991; Cruden and Varnes, 1996; Courture, 2011). The materials may move by falling, toppling, sliding, spreading, or flowing (UNISDR, 2017; USGS, 2004).

Landslides are natural events, but may turn into serious geohazards responsible for casualties and economical losses worldwide (Petley, 2012). These include loss of lives and damage to human settlements and natural structures, which present a significant constraint for the development of the zones affected. According to the World Health Organization, landslides affected an estimated 4.8 million people and caused more than 18,000 deaths, between 1998-2017 (https://www.who.int/health-topics/landslides\#tab=tab 1). However, at least $90 \%$ of losses related can be avoided if the problem is recognized before the landslide occurrence (Brabb, 1993). Therefore, the mitigation measures require to identify existing landslides, and/or to predict of future events and endangered zones. One main issue is that landslide inventories suffer from underreporting at both regional and global scales (UNISDR, 2017). Even in developed countries, the database of landslide events is usually far from complete. Significant gaps in available information additionally contribute to the shortcomings of the inventories due to the lack of routine global monitoring or cataloging systems, such as those available for hurricanes and earthquakes (Kirschbaum et al. 2009). However, mapping landslide deformation and activity is fundamental for the assessment and reduction of hazards and risks related (Zhao and $\mathrm{Lu}$, 2018).

Remote sensing data and the geospatial sceinces are very powerful tools to study the prevailing causal factors and achieve that goal (Tofani et al., 2013). Their integration leads to a standard tool known as landslide susceptibility mapping used around the world by various researchers (Guzzetti et al., 1999; Van Westen et al., 1999), which helps mapping the areas affected or model the likelihood of future landsliding based solely on the intrinsic properties of a site. The susceptibility of a given area to landslides can be determined and depicted using hazard zonation (Lin et al., 2017). Recent advances identify two sets of methods for landslide hazard zonation (LHZ), such as heuristic (knowledge-based) and data driven (statistical) approaches (Pardeshi et al., 2013).

The heuristic or qualitative approach relies on the distribution (inventory) analysis through field survey mapping, historical records, satellite images and aerial photo interpretation (Varnes,1984; Cruden, 1991; Colombo et al., 2005; Guzzetti et al. 2005; Galli et al., 2008). Other researchers use decision-action processes and weighing models, including the analytical hierarchy process (AHP) and its different derivatives (Komac, 2006; Ghosh et al. 2011; Kayastha et al. 2012; Wu et al., 2016; Meena et al., 2019). The statistical or quantitative approach include bivariate and multivariate modeling methods to minimize subjectivity (Kanungo et al., 2006). Amongst bivariate methods, weights of evidence model, weighted overlay method, frequency ratio approach, information value method and fuzzy logic method are used (Blahut et al. 2010) (Martha et al., 2013; Preuth, et al., 2010; Lee, 2005; Sarkar et al., 2006; Singh et al., 2011). Multivariate are specifically logistic regression analysis, discriminant analysis, artificial neural network (ANN) method and probabilistic approach (Guzzetti et al., 2005, Wang and Sassa, 2005; Lee et al., 2008; Kanungo et al., 2009; Pradhan et Lee, 2009; Bui et al., 2012; Calvello et al., 2013). 
Nowadays, the quantitative approach is supported by several machine learning algorithms with better accuracy. They can be single or hybrids, and amongst them are processing such as the support vector machine (SVM), Random Forest (RF), Fisher's Linear Discriminant Analysis (FLDA), Bayesian Network (BN), Logistic Regression (LR), and Naïve Bayes (NB), or more recently the AdaBoost, MultiBoost, Bagging, and Rotation Forest (Marjanovic et al., 2011; Goetz et al., 2015; Pham et al., 2016a\&b; Ada and San, 2018; Pham et al., 2018; Shirzadi et al., 2018; Cavanesi et al., 2020; Xiao, et al., 2020; Xiong et al., 2020).

Both qualitative and quantitative methods keep improving their processes to map and assess the areas affected. From that, the main objective of this paper is to map the rainfall-triggered landslides occurrence. The proposed model adapts Sudden Landslide Identification Product (SLIP) to detect on one hand the surface affected as well as the areas concerned, and the Detecting Real-Time Increased Precipitation (DRIP) approach to identify the intensity and the time of rainfall corresponding to the event. The original method is qualitative, using open-source satellite images that consequently fits Cameroon's local scientific and economic conditions. So, to notice, the approach developed in this paper is neither meant to substitute the standardized SLIP and DRIP algorithms, but to adjust the processes as possible to a context of missing data by proposing way-outs for efficient results, and to propose a complementary process modelling the survival analysis of the study sites.

\section{Description of the SLIP and DRIP methodology}

In 2019, NASA's developers proposed the SLIP and DRIP methodology to automate rainfall-induced landslide identification in Nepal, by using open-source imagery and without the use of proprietary classification software (Fayne et al., 2019). It is a two-sided approach, using satellite imagery data to approximate visible landscape changes and precipitation data to time the landslide event. The main entry is Landsat- 8 imagery and the processing are conducted in a cloud environment for a large area mapping, based on a spectral band analysis and ancillary field data.

Sudden Landslide Identification Product (SLIP) algorithm takes advantage of spectral properties of vegetation, slope, land-cover type, and soil moisture in biweekly (16 days) time steps to identify the affected area by a landslide right after the event, based on fresh bare-earth exposure, and predict areas potentially exposed to upcoming events. The spectral red band is computed for Landsat-8, band 4, and computed as a percentage between the ten composed recent images before the landslide and the most recent post-event images. Areas with at least a $40 \%$ increase in red reflectance are considered bare-earth exposed to landslide according to this criterion. To pursue, the soil moisture is assessed by adapting Normalized Multi-Band Drought Index, NMDI, of Wang and Qu (2007), to Landsat 8 spectroscopy. Basically, the NMDI monitors the soil and vegetation moisture using the following expression:

$$
N M D I=\frac{R_{860 \mathrm{~nm}}-\left(R_{1640 \mathrm{~nm}}-R_{2130 \mathrm{~nm}}\right)}{R_{860 \mathrm{~nm}}+\left(\boldsymbol{R}_{1640 \mathrm{~nm}}-R_{2130 \mathrm{~nm}}\right)}
$$

where $R_{860 \mathrm{~nm}}, R_{1640 \mathrm{~nm}}$ and $R_{2130 \mathrm{~nm}}$ represent the apparent at-sensor reflectance absorbed in the NIR and two SWIR wavelengths of the MODIS sensor measurements. However, the integration of the Landsat- 8 band 6 that is closest to $R_{1640 \mathrm{~nm}}$, gave poor results, and only bands 5 and 7 are used. The last step integrates a Digital Elevation Model's (DEM) slopes generation and thresholding. The slope values are extracted in degrees and their intervals are classified as follows: gentle $\left(0^{\circ}-20^{\circ}\right)$, fairly steep $\left(20^{\circ}-35^{\circ}\right)$, steep $\left(35^{\circ}-45^{\circ}\right)$, very steep $\left(45^{\circ}-60^{\circ}\right)$, and extremely steep $\left(60^{\circ}-90^{\circ}\right)$. All the values $\geq 20^{\circ}$ are considered to be landslide-triggering. 
Further, noticing that a predominant triggering mechanism for landslides is rainfall (Petley et al. 2005), the Detecting Real-Time Increased Precipitation (DRIP) model leverages NASA's Global Precipitation Measurement (GPM) was used. It provides precipitation data with a more precise temporal window of occurrence for each potential event (Fayne et al., 2019). The DRIP algorithm identifies the likely timing/date of peak of precipitation triggering potential landslide events and corresponding to the SLIP detected areas in a window of 16 days. Windows of 24, 48 and 72 hours are used to obtain continuous rainfall data and integrate into the model.

Therefore, the goal of these two algorithms is the landslide identification and extreme precipitation monitoring by using python 3 as programming language. In this study, the desktop environment was used for the same purpose.

\section{Methodology}

Study area

Landslide hazard needs to be assessed at various spatial scales (UNISDR, 2017). This study was carried out at a regional scale, on a subset of Cameroon's west-highlands (Fig.1) covering 3,930.35 $\mathrm{km}^{2}$. The area belongs to the Cameroon Volcanic Line (CVL), one of the several segments of the African Plate, oriented NE between 9-11 ${ }^{\circ}$ of latitude and SW 5-7 ${ }^{\circ}$ East longitude and forming a horst (Elsheikh et al., 2014; Wokwenmendam, 2019). It is an area of transition between the Cameroon's rainy and dry areas. Its morphology is complex and consists of high plateaus, volcanic massifs as well as plains or collapse basins corresponding to the graben (Balla Aboubakar et al., 2013). The three main components are the Bamenda Plateau (2,200 meters), the Bamiléké Plateau (1,400 to 1,600 meters), and the Bamoun Plateau (1000 to 1300 meters). Ages of the volcanic products along these edifices range from the Eocene (52 Ma) to the Pliocene period (Moundi et al., 2007; Moundi et al., 2008; Tchuimegnie et al., 2015). The Noun and Ndop plains are flatted terrain with average altitudes of 1000 meters while the Mbo plain with altitudes range from 700 to $800 \mathrm{~m}$, and there are several volcanic lakes. The geological formations made up of products of volcanic eruptions are lying on a basement rocks of plutono-metamorphic nature, and of Precambrian to Panafrican age (Njonfang et al., 1998; Djoukoua et al., 2008). These basement rocks are usually associated with basic rocks (amphibolite and monzodiorite) and are masked in some places by a thick volcanic cover.

Annual rainfall increases from $100 \mathrm{~mm}$ to more than $3300 \mathrm{~mm}$ in the southern part around the city of Bafoussam, and $20 \mathrm{~mm}$ to more than $2400 \mathrm{~mm}$ when evolving to the northern part around Njimom due to the high altitude (Local agrometeorology offices, Annual reports). Twelve months average temperature is between $26^{\circ}$ and $28^{\circ}$ Celsius. The vegetation mixes highlands forest and sub-tropical savannah, depending on the rainfall and the sun exposition. The population is $1,720,047$ inhabitants, with a density of 124 inhabitants per $\mathrm{km}^{2}$.

In addition to the rainfall spatial distribution (Fig.1d \& e), human activities and settlements such as agriculture or buildings mainly occupy slopes or shallows, exposing populations to natural hazards. For instance, on the $4^{\text {th }}$ and $5^{\text {th }}$ September 2018, terrain cracking followed by blocks slides damaged dozens of houses in the city of Foumban (IGMRPenaye et al., 2018; Fig.2a), caused the delocalization of hundreds of inhabitants. More recently, during the night of 27 to 28 October 2019, a long and huge rainfall of about 36 hours triggered a rotational to translational landslide in Bafoussam (IGMR-Kankeu \& Ntchantcho, 2019; Fig.2b), the deadliest in that area with 45 dead bodies found, dozens of missing people and at least 100 houses destroyed. Moreover, since the 1950's, more than 136 deaths were recorded 
in the area (Tchindjang, $2012 \&$ 2013). This context justifies the present research, to help Cameroon's government in anticipating such events and planning mitigation actions.

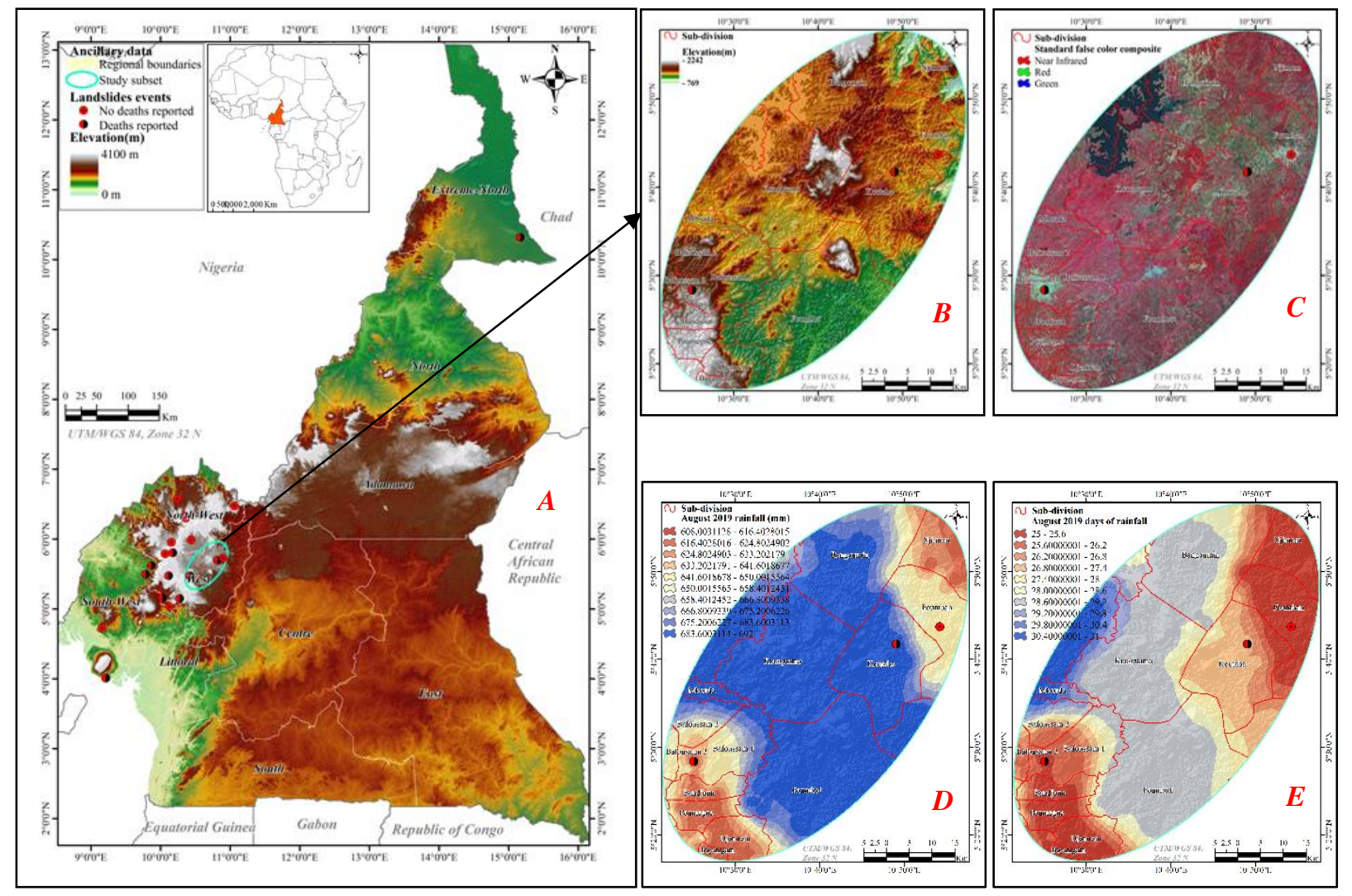

Fig.1. The study location. A) Country elevation and landslides events. B) \& C) - Subset of study elevation and Landsat OLI-TIRS image. D) Interpolated average rainfall for August. E) Interpolated days of rainfall for August.
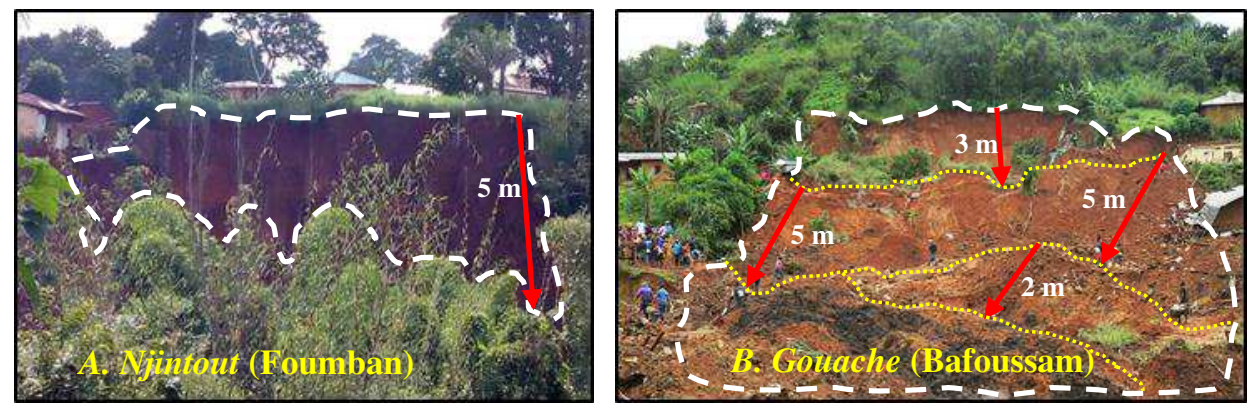

Figure 2. Unscaled partial views of the scarps leaved by landslides of Foumban (2018) and Bafoussam (2019).

Both events were sudden with transitional to rotational movements, but the one in Foumban happened in one step, while the one in Bafoussam happened in three steps (yellow dashed), justifying three main blocks/stairs. Based on the soil horizontal surface, the sliding depths (arrows) are 5 meters in Foumban, and 1 to 5 meters in Bafoussam. The affected area was $\approx 30,100 \mathrm{~m}^{2}$ in Foumban (IGMR-Penaye et al., 2018) and $\approx 15,051 \mathrm{~m}^{2}$ in Bafoussam. (IGMR-Kankeu \& Ntchantcho, 2019). 


\section{Data acquisition and preprocessing}

This experiment was conducted in a desktop script environment of licensed software Erdas Imagine 2020 version 16.6.0.1366, ArcGisPro version 2.5 and XLStats 2020.1.64570. The main entry is the landsat-8 imagery, given the fact that multispectral image analysis is a popular technique in landslide detection (Martha et al. 2016). Taking the landslide of the 28 October 2019 as reference, twelve Landsat 8 images were downloaded from the United States Geological Survey website, distributed as eleven before the event and one after (Appendix 1). Unfortunately, the cloud cover for the rainy season images is very important to stay in the 16-days temporal resolution necessary for processing, and the best images are available between December and March with at least two images per year. Freely available Landsat images are all level-1 products, delivered as digital numbers (DNs). The bands used are 2 to 7, corresponding bands blue to SWIR2 with a spatial resolution of 30 meters, and the panchromatic band was used to rescale the spatial resolution to 15 meters (Tab. 1).

Table 1. Landsat OLI-TIRS bands characteristic.

\begin{tabular}{|l|c|c|}
\hline \multicolumn{1}{|c|}{ Spectral bands } & Wavelengths Range ( $\mathbf{m m})$ & Spatial Resolution (m) \\
\hline Band 1 - Ultra Blue & $0.435-0.451$ & 30 \\
\hline Band 2 - Blue & $0.452-0.512$ & 30 \\
\hline Band 3 - Green & $0.533-0.590$ & 30 \\
\hline Band 4 - Red & $0.636-0.673$ & 30 \\
\hline Band 5 - Near Infrared & $0.851-0.879$ & 30 \\
\hline Band 6 - Shortwave Infrared & $1.566-1.651$ & 30 \\
\hline Band 7 - Shortwave Infrared & $2.107-2.294$ & 30 \\
\hline Band 8 - Panchromatic & $0.503-0.676$ & 30 \\
\hline Band 9 - Cirrus & $1.363-1.384$ & 100 \\
\hline Band 10 - Thermal Infrared & $10.60-11.19$ & 100 \\
\hline Band 11 - Thermal Infrared & $11.50-12.51$ & 30 \\
\hline
\end{tabular}

Applying the Cosine Solar TAUZ (COST) radiometric calibration model of Chavez (1996) to the stacked image, blueSWIR2, the digital numbers were converted from at-sensor radiance to top-of-atmosphere (TOA) reflectance via solar correction, and rescaled from 64-bit to unsigned 8-bit. Therefore, atmospheric corrections and haze reduction have helped to remove other noises and then approximate values of surface reflectance. The last step concerned the topographic correction that had addressed altitude artifacts. For the purpose of rainy season's land cover estimation, a classification map, change detection image and area expand function were applied (Appendix 2).

The other entry is the Shuttle Radar Topography Mission (SRTM) image of the area with a spatial resolution of 30 meters. It was also downloaded from the USGS website and preprocessed by using the "void fill" method to create a Digital Elevation Model (DEM) and reduce the errors of commission in flat areas where landslides are unlikely, such as riverbeds, which may have similar red reflectance and moisture characteristics (Jiménez-Perálvarez et al. 2011; Fayne et al., 2019). Its integration into the model helps defining the slopes threshold for landslide triggering. 
Another entry concerns the precipitation data. These data were combined from three main sources. The Tropical Rainfall Measuring Mission (TRMM) (Braun, 2011), Tropical Applications of Meteorology using Satellite data (TAMSAT) (Maidment et al., 2014) and some local meteorology services.

\section{Adapted SLIP algorithm}

The first step is defining the soil exposure, i.e., the percentage of non-vegetated land. Fayne et al. (2019) proposed it as a rate of change in the red band reflectance between the current image before the landslide and a composed image of the ten red bands of the images before the landslide. The formula is expressed as follows:

$$
\% \operatorname{Red}_{\text {change }}=\left(\frac{\operatorname{Red}_{\text {current }}-\boldsymbol{R e d}_{\text {composite }}}{\operatorname{Red}_{\text {composite }}}\right) * 100
$$

Where Red $_{\text {current }}$ is the most recent Red band during or just after the landslide and is the ten recent red bands just before the landslide. Then, the images should be collected for consecutives 16-days. In the present study, regarding the gap of almost ten months in the same year between two Landsat 8 usable images, the percentage formula described above was leading to infinite values. Then the red difference was modified to an Inverse Normalized Difference Vegetation Index, INDVI, to assess the non-vegetated land. The INDVI is proposed as the spectral difference between the red and the NIR wavelength, as follows:

$$
\text { INDVI }=\frac{\text { Red }- \text { NIR }}{\operatorname{Red}+\text { NIR }}
$$

After an average of the INDVI was computed for the ten oldest images, referring to the landslide of the 28 October 2019 in Bafoussam. Then, the average INDVI was subtracted from December 2019 INDVI and the resulting image was normalized in percentage to obtain the fraction of non-vegetated land:

$$
\text { INDVIn }=\frac{\text { INDVI }- \text { INDVImin }}{\text { INDVImax }- \text { INDVImin }} * 100
$$

Where INDVIn stands for the normalized INDVI image, min and max are the minimum and the maximum of the INDVI. Values starting at $40 \%$ were selected as indicators for soil exposure to landslides as proposed by Fayne et al. (2019). A binned image was then created, with $\boldsymbol{O}$ for vegetated areas and $\boldsymbol{I}$ for non-vegetated areas, i.e., bare soil. Then, the vegetated class was expanded with factor 2 to approximate the land surface coverage in the rainy season, according to the classification statistics (Appendix 2).

Further, the soil moisture was assessed by using two indices. On one hand, the Modified Normalized Multi-Band Drought Index (MNMDI) (Fayne et al., 2019) was computed between the near infrared (NIR) and the shortwave infrared (SWIR2) bands:

$$
\text { MNMDI }=\frac{\text { NIR }- \text { SWIR2 }}{\text { NIR }+ \text { SWIR2 }}
$$

To confirm and complete the soil moisture information, the hydrothermal index composite was computed on the other hand. This index is used to enhance soils, rocks and minerals, as well as vegetation cover at a regional scale, based on a multiple ratios approach computation between the visible and infrared wavelengths (Pour, 2014). The concerned band ratios are $S W I R I / S W I R(6 / 7)$, Red/Blue (4/2), and NIR/Red (5/4), while the result is a three principal components analysis image (Erdas, 2020). A linear regression was performed between each principal component and the MNMDI image, showing that the hydrothermal index PC3 was positively correlated to MNMDI with the highest determination 
coefficient $\left(R^{2}\right)$ up to $82 \%$ (Appendix3). The hydrothermal PC3 and the MNMDI stretching ranges are [0-11] and [$1.205-0.915]$ respectively, their moisture thresholds were identified between [1.5 - 11] and [0.08 - 0.915] to create binned images. By adding up the two binned images, a new one was obtained, and then weighted 0 for no humidity and 0.75 for moisture.

As last step, the slope inclination value was computed based on the preprocessed DEM. In the Cameroon's landslides history and for the western highlands in particular, the lowest slope for the hazard's occurrence was at Koutaba (2001, 2 deaths) on a slope of $22^{\circ}$ (IGMR-Penaye et al., 2018; IGMR-Kankeu \& Ntchantcho, 2019). For this reason, we choose the threshold $\mathbf{2 0}^{\circ}$, proposed by Fayne et al. (2019) as significant to trigger landslide. After performing the hillshade processing to better highlight summits and valleys, the slope image was extracted in degrees. A binned image was created with $\boldsymbol{0}$ for slopes less than $20^{\circ}$ and $\boldsymbol{0 . 5}$ for slopes at or above $20^{\circ}$. The three conditioned layers binned values are recorded in table 2.

Table 2. SLIP conditioned layers.

\begin{tabular}{|l|l|l|}
\hline \multirow{2}{*}{} & \multicolumn{2}{|l|}{ Conditions for LHZ } \\
\cline { 2 - 3 } & Excluded & Included \\
\hline Bare soil & $\mathbf{0}$ & $\mathbf{1}$ \\
\hline Soil moisture & $\mathbf{0}$ & $\mathbf{0 . 7 5}$ \\
\hline Slope inclination & $\mathbf{0}$ & $\mathbf{0 . 5}$ \\
\hline
\end{tabular}

The three layers were integrated using a simple weighted linear combination (SWLC) to map the areas where the conditions were met for sudden landslides. There are eight different values corresponding to the LHZ codes (Tab. 3). The SLIP process is described in figure 3 and the layers are represented in figure 4.

Table 3. LHZ codes and explanation.

\begin{tabular}{|l|l|}
\hline Classes codes & Conditions met \\
\hline 0 & None \\
\hline 0.5 & Slope inclination \\
\hline 0.75 & Soil moisture \\
\hline $\mathbf{1}$ & Bare soil \\
\hline 1.25 & Soil moisture \& Slope inclination \\
\hline 1.5 & Bare soil \& Slope inclination \\
\hline 1.75 & Bare soil \& Soil moisture \\
\hline 2.25 & Bare soil \& Soil moisture \& Slope inclination \\
\hline
\end{tabular}




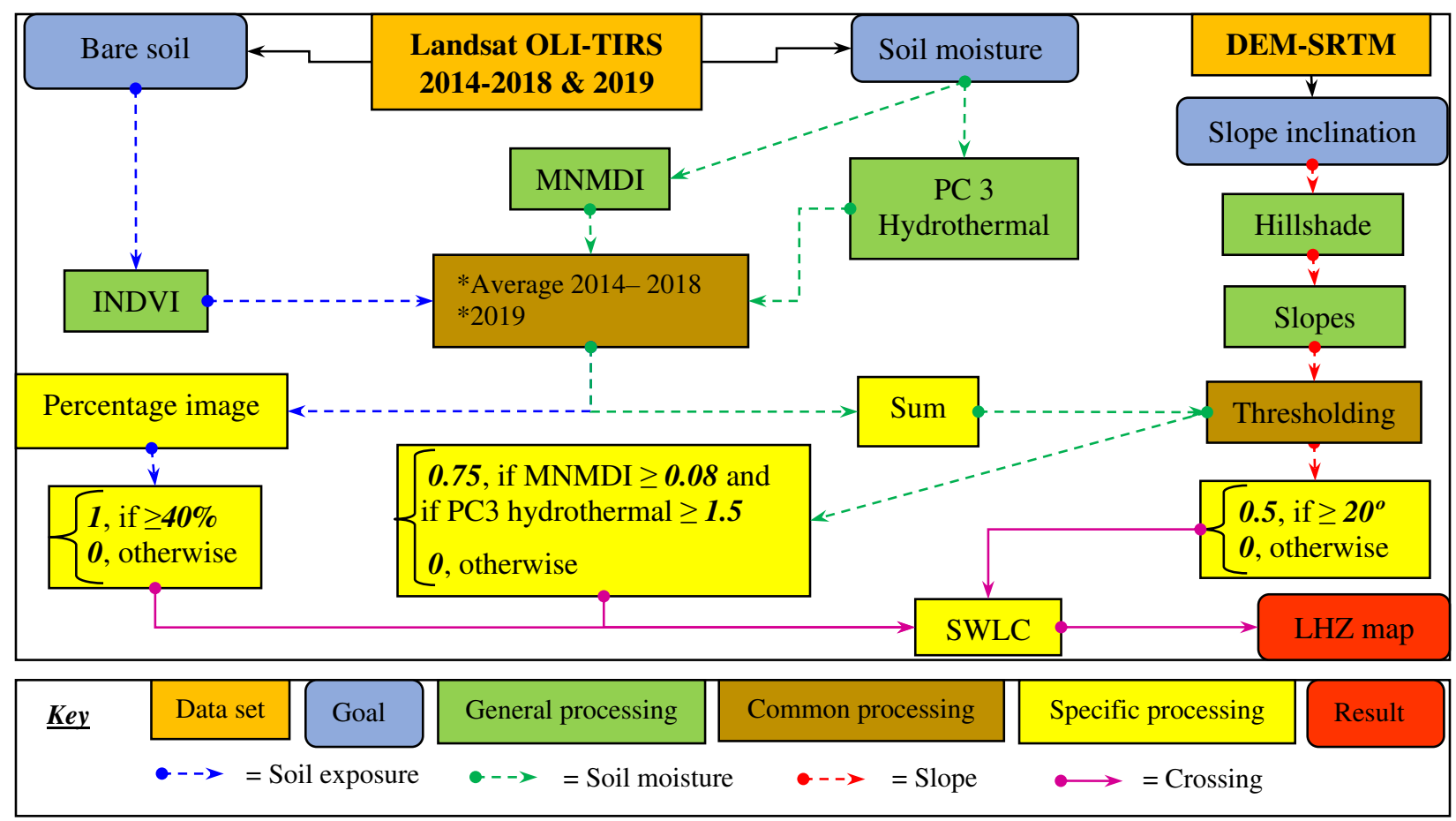

Figure 3. Workflow of the SLIP process.

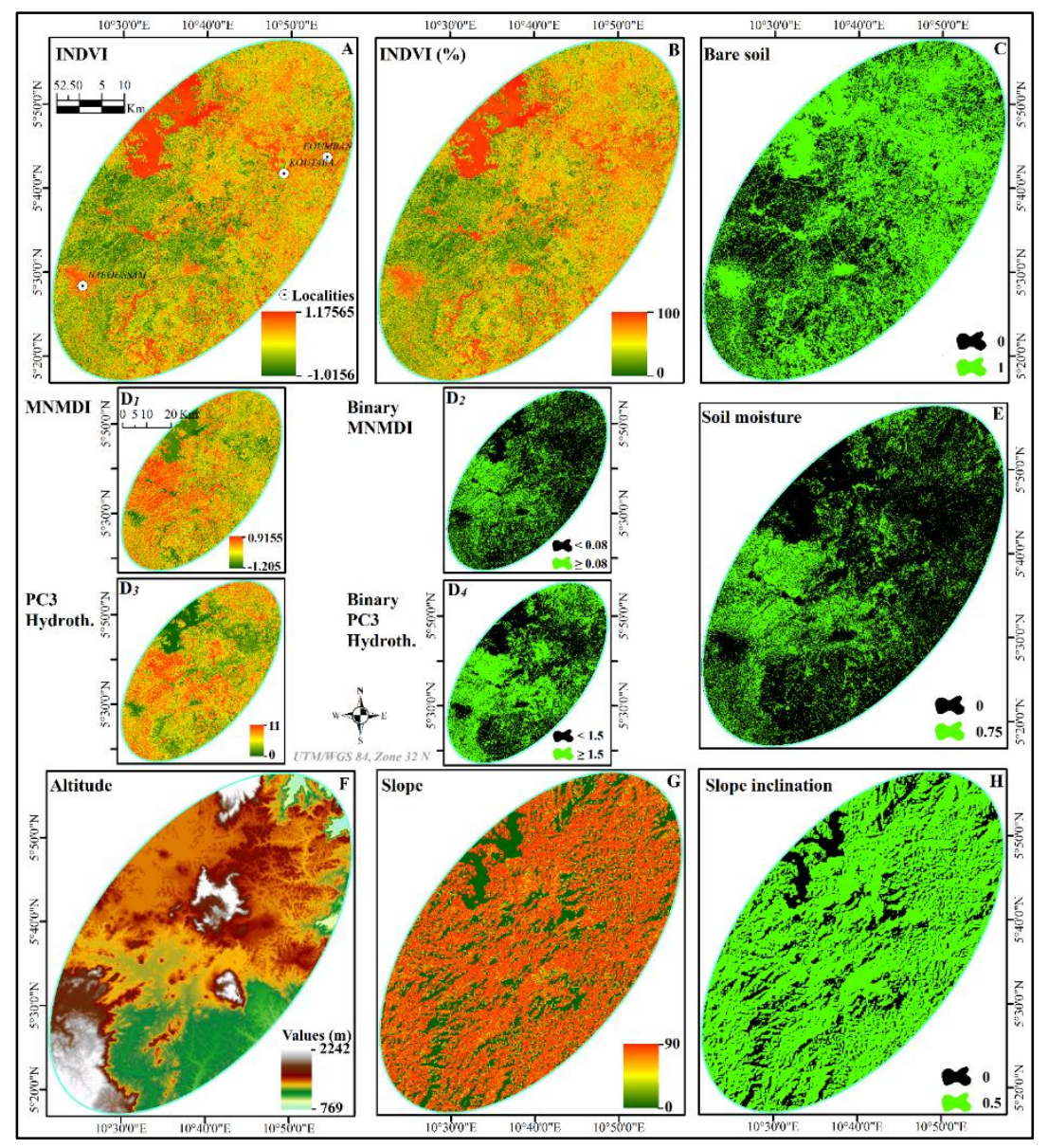

Figure 4. SLIP stretched and conditioned layers. 
Only remains the triggering factor identified as a long and huge rainfall. The DRIP algorithm helps modelling it.

\section{Adapted DRIP algorithm}

The DRIP tool is adapted as the rainfall intensity and threshold corresponding to the SLIP landslide mapping. Monthly precipitations of the west Cameroon were computed between 1948 and 2017 for Africa ${ }^{8}$, completed for years 2018 and $2019^{9}$ (Table 2). According to the Tropical Applications of Meteorology using Satellite and ground-based observations (TAMSAT) data, especially its TRMM Multi-satellite Precipitation Analysis (TMPA) datasets component and mapping models, daily rainfall for the Cameroons' west-highlands were between $6 \mathrm{~mm}$ and more than $10 \mathrm{~mm}$ between 1983 and 2012 (Maidment et al., 2014). The annual highest rainfall period is between the second decade of June and the first decade of October, with at least 15 millimeters to more than 25 millimeters per day (Maidment et al., 2014; Dezfuli et al., 2017).

The rainfall data collected by the local agro-meteorology offices (October 2019) assess the rainfall of 28 to 29 October in Bafoussam up to $81 \mathrm{~mm}$, in about 36 hours, before the landslide. This represents $22 \%$ of the $384 \mathrm{~mm}$ recorded for that month (Appendix 4). Ten groups of rainfall records were defined between June and October, that is 50 observations (Appendix 4). The month's selection is explained by the fact that all the landslides in Cameroon occurred in that five months interval, corresponding to the full rainy season (Tab. 4).

The rainfall increases from June to September with highest records in August, and decreases in October, before stopping in November. The trends are the same for the number of rainy days, although some local differences can be barely noticed between two zones. In addition, the rainfall zonation was done from the lower (Zone 1) to the higher (zones 9 and 10) records. Samples of zones 1, 4 and 8 illustrate these two statements for 2019 (Fig.5).

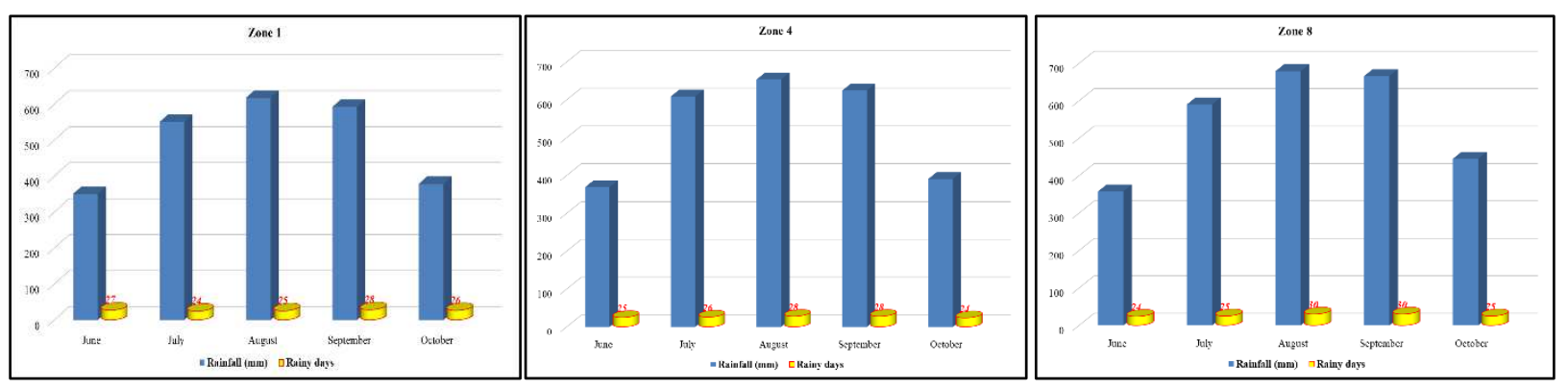

Figure 5. Monthly rainfall and rainy days sampled for three zones of the study area in 2019.

The general trends give an average rainfall of 2,615 $\mathrm{mm}$ for $1948-2018$ and 2,573 $\mathrm{mm}$ in 2019, representing respectively $79 \%$ and $78 \%$ of the $3,300 \mathrm{~mm}$ maximum annual rainfall. August represents $25 \%$ of the five months and October records about 14\% (Fig.6). Moreover, the $81 \mathrm{~mm}$ of rainfall preceding the October 2019 landslide event represent $3.1 \%$ of the five months and almost four times the total daily mapped by Maidment et al. (2014) and Dezfuli et al. (2017).

\footnotetext{
${ }^{8}$ https://fr.climate-data.org/afrique/cameroun/west-1367/

9 https://weather-and-climate.com/average-monthly-Rainfall-Temperature-Sunshine
} 

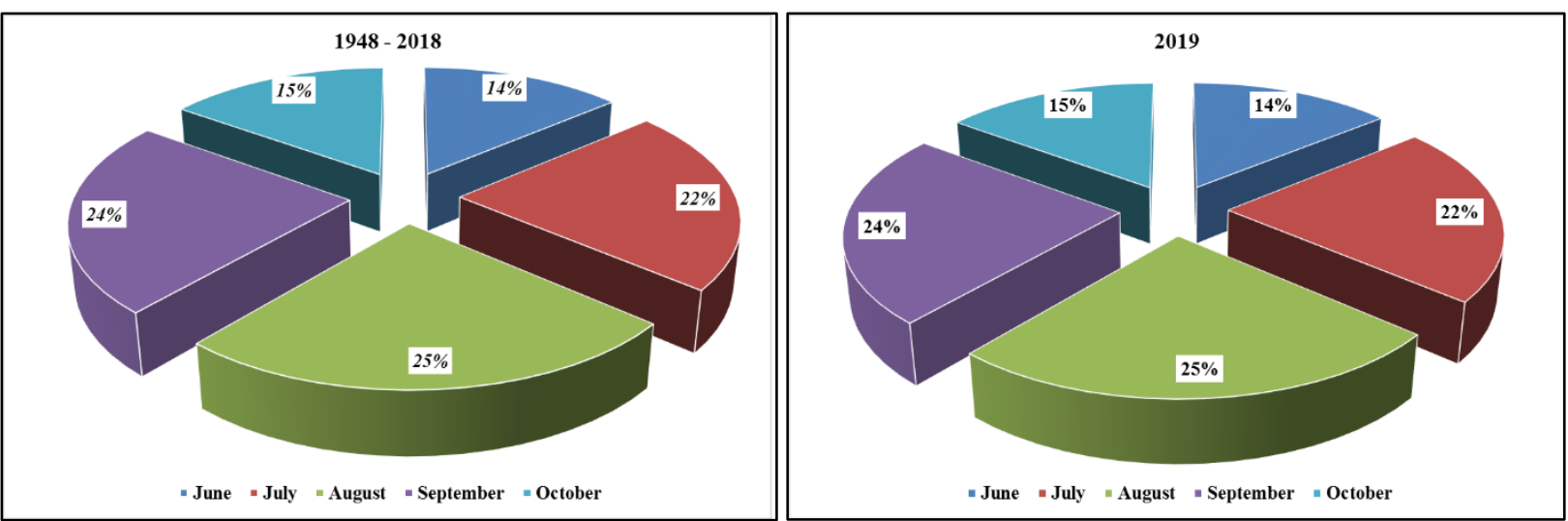

Figure 6. Percentage of monthly rainfall between June and October.

Table 4. Landslide causes and consequences in Cameroon to the best of recording.

\begin{tabular}{|c|c|c|c|}
\hline Month/Year & Location & Causes & Main casualties and losses \\
\hline September 1954 & Nchingang, Lebialem & $\begin{array}{l}\text { Slopes' agriculture, woodcutting and } \\
\text { huge rainfall }\end{array}$ & $\begin{array}{l}\text { Bridges destroyed followed by } \\
\text { flooding }\end{array}$ \\
\hline September 1956 & Beine, Lebialem & Slopes' agriculture and huge rainfall & $\begin{array}{l}3 \text { deaths; houses and bridges destroyed } \\
\text { followed by flooding; farms flooded } \\
\text { and destroyed }\end{array}$ \\
\hline September 1957 & Fomenji, Lebialem & Huge rainfall & 12 deaths, bridges and farms destroyed \\
\hline August 1973 & Fonengé, Lebialem & Huge rainfall & $\begin{array}{l}1 \text { death; dozens of houses destroyed; } \\
300 \text { homeless }\end{array}$ \\
\hline August 1978 & Fossong-Wetcheng (Dshang) & Huge rainfall & 6 deaths; farms destroyed \\
\hline June 1988 & $\begin{array}{l}\text { Bamboko, Melong mt } \\
\text { Manengouba }\end{array}$ & Huge rainfall & $\begin{array}{l}8 \text { deaths; bridges and houses } \\
\text { destroyed }\end{array}$ \\
\hline June 1991 & Pinyin & Thundershowers & Plantations destroyed \\
\hline July 1991 & Limbe, Mt Cameroun & Public works on slopes; Huge rainfall & 1 death; 1 house destroyed \\
\hline September 1991 & Pinyin, Santa, Bamenda & Slopes' agriculture and huge rainfall & 12 deaths; 2 houses destroyed \\
\hline 12 September 1992 & Santa, Bamenda & Slopes' agriculture and huge rainfall & 12 deaths; 5 houses destroyed \\
\hline September 1992 & Fomenji, Abi, Fonengé & Slopes' agriculture and huge rainfall & $\begin{array}{l}12 \text { deaths; houses, bridges and farms } \\
\text { destroyed }\end{array}$ \\
\hline September 1993 & Bafaka & Huge rainfall & Farms and houses destroyed \\
\hline September 1994 & Fomenji, fotang,Fonengé & Slopes' agriculture and huge rainfall & 6 bridges and 10 houses destroyed \\
\hline September 1995 & Bafaka, Ndian, Mt Rumpi & $\begin{array}{l}\text { Earthquakes (intensity VII on Richter } \\
\text { scale) and rainfall }\end{array}$ & $\begin{array}{l}3 \text { deaths; } 1 \text { house, farms and forests } \\
\text { destroyed. }\end{array}$ \\
\hline September 1997 & Sho, Belo & $\begin{array}{l}\text { Huge rainfall; perched water source; } \\
\text { slopes' agriculture; woodcutting }\end{array}$ & $\begin{array}{l}2 \text { deaths; } 1 \text { house, } 1 \text { road destroyed } \\
\text { followed by several weeks of traffic } \\
\text { interruption; farms destroyed. }\end{array}$ \\
\hline September 1997 & $\begin{array}{l}\text { Gouata, Dschang (Mt } \\
\text { Bamboutos) }\end{array}$ & Huge rainfall & 1 death and farms destroyed \\
\hline September 1997 & Batié & Sand digging and huge rainfall & Farms destroyed \\
\hline July 1998 & Bingo, Belo & Huge rainfall & 5 deaths and 3 houses destroyed \\
\hline August 1998 & Bamumba, wabane Lebialem & Slight earth shaking and rainfall & $\begin{array}{l}5 \text { injured; } 11 \text { houses destroyed; } \\
\text { bridges and farms destroyed. }\end{array}$ \\
\hline August 1998 & Abi, Ako, Atsuela, Babong & Rainfall & 1 injured; houses and farms destroyed \\
\hline September 1998 & Anjin, Belo & $\begin{array}{l}\text { Slopes' agriculture, woodcutting and } \\
\text { huge rainfall }\end{array}$ & $\begin{array}{l}2 \text { deaths; } 1 \text { house and farms } \\
\text { destroyed; }\end{array}$ \\
\hline September 2000 & Rom Nwah & $\begin{array}{l}\text { Earthquakes (intensity IV on Richter } \\
\text { scale) and rainfall }\end{array}$ & $\begin{array}{l}6 \text { deaths; } 17 \text { injured; } 7 \text { houses } \\
\text { destroyed; }\end{array}$ \\
\hline June 2001 & Limbé & $\begin{array}{l}\text { Earthquakes (intensity IV on Richter } \\
\text { scale) and rainfall }\end{array}$ & $\begin{array}{l}24 \text { deaths, } 2800 \text { homeless, } 120 \text { houses } \\
\text { destroyed }\end{array}$ \\
\hline 10 September 2002 & Bana-Bafang & Slopes' agriculture and huge rainfall & 10 deaths ; houses destroyed \\
\hline 20 July 2003 & Magha'a and Atsuela & $\begin{array}{l}\text { Slopes' agriculture, breeding, } \\
\text { woodcutting and huge rainfall }\end{array}$ & $\begin{array}{l}22 \text { deaths; } 50 \text { deaths cattle; houses; } \\
\text { roads and farms destroyed. }\end{array}$ \\
\hline August 2003 & Bafou & Rainfall & 2 deaths; 1 house destroyed \\
\hline August 2003 & Wabane & Huge rainfall and flooding & 1 death \\
\hline 27 September 2007 & Abuh & Rainfall & Plantations destroyed \\
\hline September 2008 & Fondonera & Huge rainfall & Farms destroyed \\
\hline
\end{tabular}




\begin{tabular}{|c|c|c|c|}
\hline October 2008 & Moumé-Bafang & Huge rainfall & $\begin{array}{l}1 \text { death; } 103 \text { homeless; } 12 \text { houses and } \\
1 \text { road destroyed; }\end{array}$ \\
\hline October 2009 & Bamenda-Akum & $\begin{array}{l}\text { Huge rainfall causing collapse and } \\
\text { blocks subsidence }\end{array}$ & $\begin{array}{l}\text { Main road destroyed with several days } \\
\text { of traffic interruption }\end{array}$ \\
\hline October 2010 & Bamenda & $\begin{array}{l}\text { Huge rainfall causing collapse and } \\
\text { blocks subsidence }\end{array}$ & $\begin{array}{l}7 \text { deaths; } 7 \text { houses destroyed; } 50 \\
\text { homeless; }\end{array}$ \\
\hline 23 October 2011 & Koutaba & Bare slopes and huge rainfall & 2 deaths; \\
\hline $\begin{array}{l}\text { August, September } \\
\text { and October of every } \\
\text { year including } 2012 \\
\text { to } 2017\end{array}$ & Mbo and Ndop plains & $\begin{array}{l}\text { Huge rainfall, slopes' agriculture and } \\
\text { breeding }\end{array}$ & Farms and roads destructions \\
\hline $\begin{array}{l}4 \& 5 \text { September } \\
2018\end{array}$ & Foumban & $\begin{array}{l}\text { Huge rainfall causing collapse and } \\
\text { blocks subsidence }\end{array}$ & Houses and roads destroyed \\
\hline $\begin{array}{l}28 \& 29 \text { October } \\
2019\end{array}$ & Bafoussam & $\begin{array}{l}\text { Slopes' agriculture, breeding, } \\
\text { woodcutting and huge rainfall }\end{array}$ & $\begin{array}{l}45 \text { deaths; } 300 \text { homeless; dozens of } \\
\text { houses destroyed }\end{array}$ \\
\hline
\end{tabular}

(Sources: Ayonghe et al., 2002; Tchindjang, 2013; (IGMR-Penaye et al., 2018; IGMR-Kankeu \& Ntchantcho, 2019)

From the table 4 above (including years 2012 to 2017), approximately 53 landslides have occurred in Cameroon between 1954 and 2019, and were all directly related to huge rainfall. As figure 7 illustrates, the highest month frequency corresponds to September with 24 occurrences (45\%), followed by August with 12 occurrences (22\%), October with 11 occurrences (21\%), while June and July record the lowest same frequency of 3 occurrences (6\%).

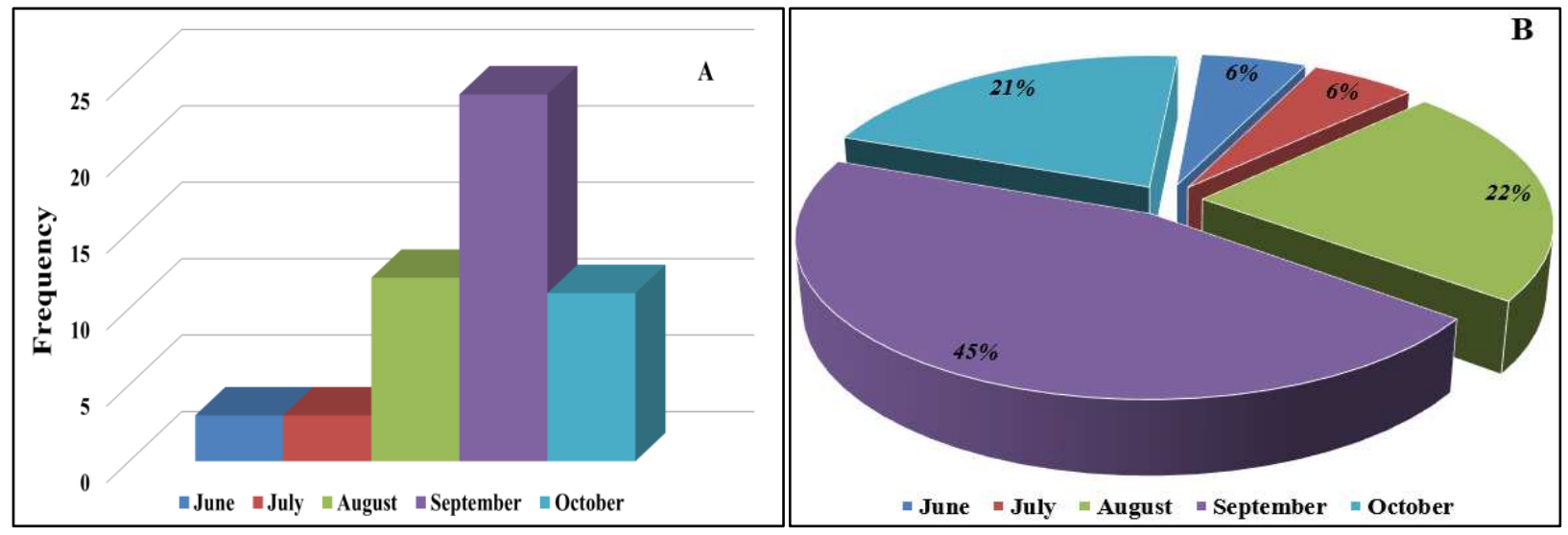

Figure 7. Monthly frequency (A) and percentage (B) of landslides between 1954 and 2019.

Further, their statistical distribution and variability were assessed by using the Weibull distribution. This method calculates a cumulative distribution (CDF) or a probability density function (PDF) using the following equation:

$$
\boldsymbol{f}(\boldsymbol{x})=\frac{\gamma}{\alpha}\left(\frac{x-\mu}{\alpha}\right)^{\gamma-1} \exp \left(-((x-\mu) / \alpha)^{\gamma}\right) \quad \text { With } \quad x \geq \mu ; \gamma, \alpha>0
$$

Where the parameters are $\boldsymbol{\gamma}$ the shape, $\boldsymbol{\mu}$ the location and $\boldsymbol{\alpha}$ the scale. Because the Weibull model studies strength and failure of a system in relation with time (Klein, 2009), this study assesses the stronger relationship to the failures between rainfall and days of rainfall for the period 1948-2018 average, and then for the year 2019, setting $\boldsymbol{\gamma}=\mathbf{0 . 5}$. The rainfall and days of rainfall data were rescaled by using the following ratios:

\section{[monthly rainfall $\div$ monthly total of rainy days] \\ [monthly rainy days $\div$ monthly total days]}

The probabilities of failure and success were defined for both sets of data as:

$$
\begin{gathered}
\operatorname{PF}(\mathrm{x})=\frac{n_{x}}{N+1} \\
\operatorname{PS}(\mathbf{x})=1-P F
\end{gathered}
$$


With $P F$ and $P S$ representing the probability of strength to failure and the probability of success. Then, their probabilities of strength to failure are suitable to be used as the $z$ value in the standard PDF computation, which is defined as a normal distribution. Purposely and based on the data, the averages $(\approx 3$ and $\approx 4)$ and the standard deviations $(\approx 1)$ of the mean daily rainfall and days of rainfall were computed for the two periods, and the PDF curves were superimposed on each other to find intersections (Fig.8a\&b).
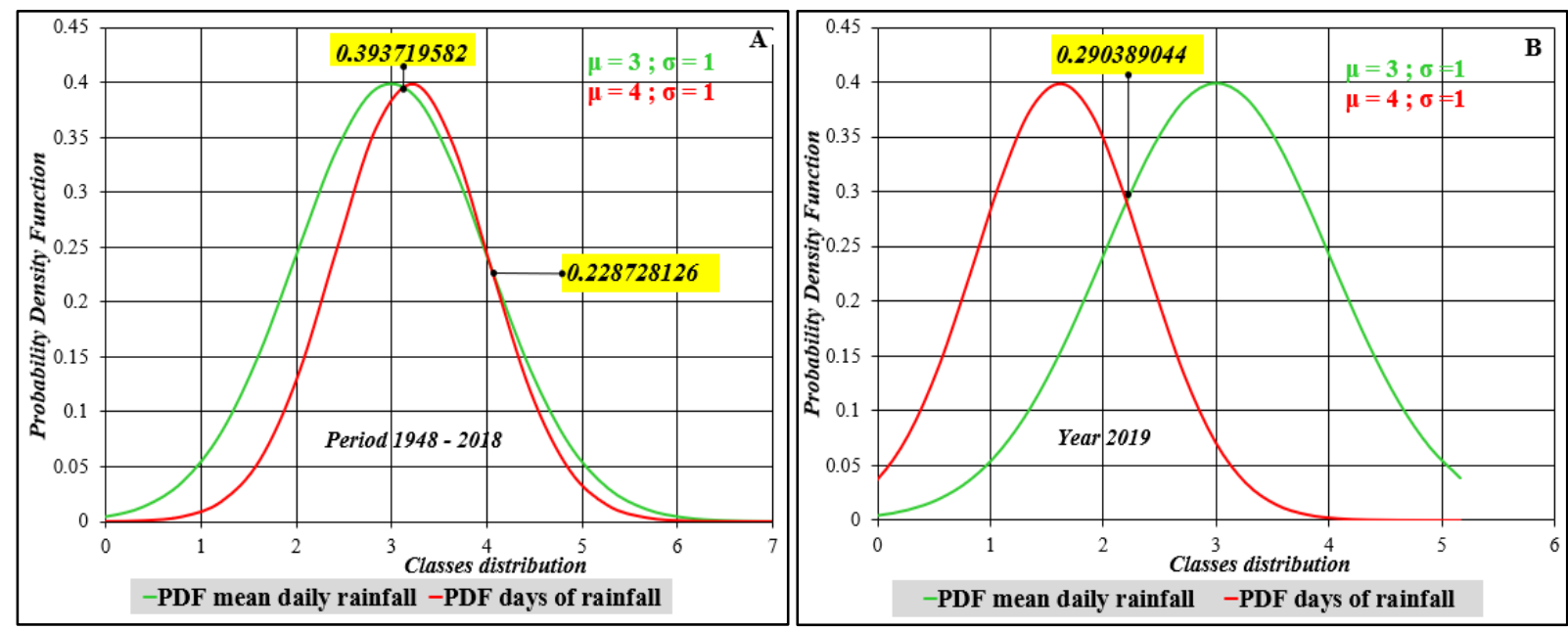

Figure 8. Individual PDF curves and their intersections before (A) and in (B) 2019.

From the intersection of the two PDF curves, a set of thresholds were defined in a conditioning algorithm, with six explanatory variables (X), i.e., before landslide (1948-2018) and one dependent variable (Y), i.e., after landslide (2019). The conditioning algorithm is written as follows:
i. $\quad X_{1.1 .}=\left\{\begin{array}{lc}\mathbf{1} & \text { if } \boldsymbol{P D F}_{\mathbf{1 9 4 8 - 2 0 1 8}} \text { rainfall frequency } \leq \mathbf{0 . 2 2 9} \\ \mathbf{0} & \text { Otherwise }\end{array}\right.$
ii. $\quad X_{1.2 .}=\left\{\begin{array}{lc}\mathbf{1} & \text { if } \mathbf{0 . 2 2 8}>\boldsymbol{P} \boldsymbol{D} \boldsymbol{F}_{\mathbf{1 9 4 8 - 2 0 1 8}} \text { rainfall frequency } \leq \mathbf{0 . 3 9 4} \\ \mathbf{0} & \text { Otherwise }\end{array}\right.$
iii. $\quad X_{1.3 .}=\left\{\begin{array}{cc}\mathbf{1} & \text { if } \mathbf{0 . 3 9 4}>\boldsymbol{P} \boldsymbol{D} \boldsymbol{F}_{\mathbf{1 9 4 8}-\mathbf{2 0 1 8} \text { rainfall frequency }} \\ \mathbf{0} & \text { Otherwise }\end{array}\right.$
iv. $\quad X_{2.1 .}=\left\{\begin{array}{cc}\mathbf{1} & \text { if } \boldsymbol{P D F}_{\mathbf{1 9 4 8 - 2 0 1 8}} \text { days of rainfall frequency } \leq \mathbf{0 . 2 2 9} \\ \mathbf{0} & \text { Otherwise }\end{array}\right.$
v. $\quad X_{2.2 .}=\left\{\begin{array}{lcc}\mathbf{1} & \text { if } \mathbf{0 . 2 2 9}>\boldsymbol{P} \mathbf{D F}_{\mathbf{1 9 4 8 - 2 0 1 8}} \text { days of rainfall frequency } \leq \mathbf{0 . 3 9 4} \\ \mathbf{0} & \text { Otherwise }\end{array}\right.$
vi. $\quad X_{2.3 .}=\left\{\begin{array}{cc}\mathbf{1} & \text { if } \mathbf{0 . 3 9 4}>\boldsymbol{P} \mathbf{D F}_{\mathbf{1 9 4 8 - 2 0 1 8}} \text { days of rainfall frequency } \\ \mathbf{0} & \text { Otherwise }\end{array}\right.$
vii. $Y=\left\{\begin{array}{cc}\mathbf{1} & \text { if } \boldsymbol{P D F}_{\mathbf{2 0 1 9}} \leq \mathbf{0 . 2 9} \\ \mathbf{0} & \text { Otherwise }\end{array}\right.$

Then the probability of rainfall-triggered landslide is calculated by performing the logistic function. This is a classification algorithm useful for predicting binary outcome (1/0, Yes/No, True/False) given a set of predictor variables. It allows computing a multivariate regression between a binary dependent variable and several independent variables (Atkinson and Massari, 1998). Multiple logistic regression assumes that observations are independent and the natural log of the odds ratio and the measurement variables have a linear relationship. The quantitative relationship between the occurrence and its dependency on several variables can be expressed in the form of a logit function such as: 


$$
\boldsymbol{P}_{(E v \cdot=1)}=\frac{e^{Z_{E v}}}{1+e^{Z_{E v}}}
$$

Where $\boldsymbol{P}_{\boldsymbol{E}}$, is the probability of an event occurring. In this case, the event is the daily rainfall threshold to trigger the landslide, and then being equal to $\boldsymbol{I}$ in the interval $(0 ; 1) . Z_{E v}$. is the linear relationship of the event's occurrence with independent variables, and it is expressed as:

$$
Z_{E v .}=b_{0}+b_{1} x_{1}+b_{2} x_{2}+\cdots b_{n} x_{n}
$$

Where $\boldsymbol{b}_{\boldsymbol{0}}$ is the intercept of the model, the $\boldsymbol{b}_{\boldsymbol{i}}(\boldsymbol{i}=\mathbf{0}, \mathbf{1}, \mathbf{2}, \ldots, \mathbf{n})$ are the slope coefficients of the logistic regression model, and the $\boldsymbol{x}_{\boldsymbol{i}}(\boldsymbol{i}=\mathbf{0}, \mathbf{1}, \mathbf{2}, \ldots, \mathbf{n})$ are the explanatory variables. Figure 9 synthesizes the processing.

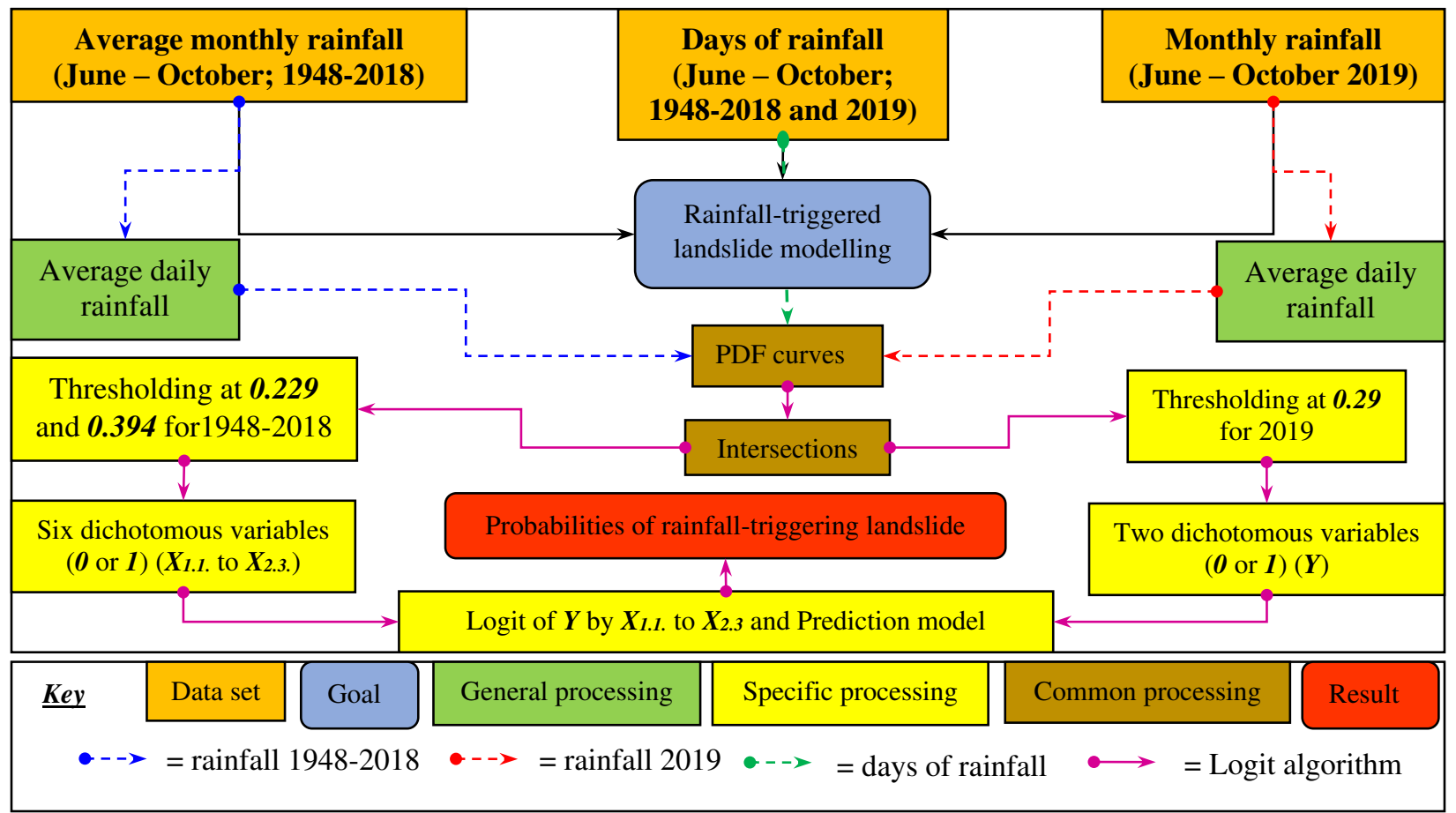

Figure 9. Workflow of the DRIP process

Modelling the rainfall-triggered landslides as sites survival analysis

The method of Caine (1980) was used to model the relation of rainfall to landslides. This process suggests a general threshold that works for time paces between 10 minutes and 10 days, using the rainfall intensity $(\mathbf{I}, \mathbf{m m} / \mathbf{h r})$ and duration $(\boldsymbol{D}, \boldsymbol{h r})$. Here, the quantity of monthly rainfall was expressed as a function of the duration $(\boldsymbol{Q}, \boldsymbol{m m} / \mathbf{h r})$ in the following equation:

$$
I=\frac{Q}{D}=\alpha D^{\beta} \Leftrightarrow Q=\alpha D^{\beta}
$$

The values of $\boldsymbol{\alpha}$ and $\boldsymbol{\beta}$ are defined by using the Cobb-Douglas regression model in the formulation:

$$
\log (Q)=\log (\alpha)+\beta * \log (D)
$$

The second step consists in assessing the spatial variability of the phenomenon. A spatial autoregressive model (SAR) enables to decompose the spatial process for a known site $\boldsymbol{s}$, based on a random variable $\boldsymbol{Z}_{(\boldsymbol{s})}$, as follows:

$$
Z_{(s)}=\mu_{(s)}+\varepsilon_{(s)}
$$




$$
\begin{gathered}
\boldsymbol{\mu}_{(s)}=\left[Q_{(s)} ; H H Z_{(s)}\right] \\
L H Z_{(s)}=a Q^{b}(s) \Leftrightarrow \mu_{(s)}=a Q^{b}(s)
\end{gathered}
$$

values of $\boldsymbol{a}$ and $\boldsymbol{b}$ are similarly extracted as for $\boldsymbol{\alpha}$ and $\boldsymbol{\beta}$.

Therefore:

$$
Z_{(s)}=L H Z_{(s)}+\varepsilon_{(s)}=\alpha a D^{\beta b}+\varepsilon_{(s)}
$$

Where, $\boldsymbol{\mu}($.$) is the spatial characterization and \boldsymbol{\varepsilon}(\boldsymbol{s})$ is a centered random variable or error, $\boldsymbol{\alpha}$ and $\boldsymbol{a}$ result from computing exponential of the intercept, and $\mathbf{L H Z}(s)$ integrates the four binary codes corresponding to at least two conditions met (see table3) plus the fifth spatially closest code.

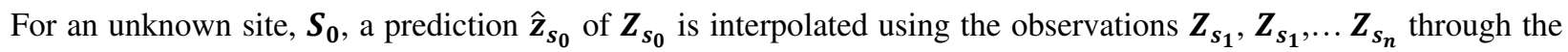
kriging process, expressed such as:

$$
\widehat{z}_{s_{0}}=\lambda_{1} Z_{s_{1}}+\lambda_{2} Z_{s_{2}}+\cdots+\lambda_{n} Z_{s_{n}}
$$

Then follows the Cox proportional hazards model. Originally, this model is used on the medical field to assess the probability that an individual will experience an event (for example, death) within a small-time interval, given that the individual has survived up to the beginning of the interval (Cox, 1972). The methodology mostly looks at the probability that given hazards, as the opposite phenomenon of hazards, may occur for a given actual occurrence (https://www.gislounge.com/proportional-hazard-modeling-gis/). Although these models were not originally oriented spatial, they have been progressively integrated in geospatial analysis. Recent applications concerned fire hazard probabilities (Cyr et al., 2007) and factors of a space colonization (Baudains et al., 2015). Theoretically, the hazard function for this case study is expressed such as:

$$
\lambda\left(t \mid Z_{s_{i}}\right)=\lambda_{0}(t) \exp \left(\beta_{1} Z_{s_{1}}+\beta_{2} Z_{s_{2}}+\cdots+\beta_{n} Z_{s_{n}}\right)=\lambda_{0}(t) \exp \left(\beta * \bar{Z}_{s_{1}-s_{n}}\right)
$$

It gives the hazard function at time $\boldsymbol{t}$ for any unknown site $\boldsymbol{S}_{\mathbf{0}}$ with covariate vector that are the known sites of occurrence $\boldsymbol{Z}_{\boldsymbol{s}}$. There are five known sites that are, one ( 1 ) in Koutaba, three in Foumban (3) and one in Bafoussam (1). There are also nine verification or unknown sites, distributed such as two in Koutaba, two in Bafoussam and five in Bafoussam. The model is built for the entire period, 1948-2019.

\section{Results and findings}

\section{The LHZ map in relation with sites of landslides events}

The SLIP outcome is a map identifying the landslide zones of occurrence in eight classes (Fig.10). The lowest class value, $\boldsymbol{O}$, stands for none condition met and the highest-class value, 2.25 , corresponds to the landslide full conditions. The study subset is widely exposed to landslides hazard at different degrees. The visual patterns appraisal was conducted by zooming on the three localities of Koutaba, Foumban and Bafoussam, subject to landslides in October, 2011, September 2018 and October 2019. Generally, at least two conditions are met for the occurrence of the event and the dominant trend is the combination 'bare soil \& slope inclination' (1.5) conditions.

i) In Koutaba, the occurrence site matches classes coded 1.5 (Bare soil \& Slope inclination), 1.75 (Bare soil \& Soil moisture) and 2.25 (Bare soil \& Soil moisture \& Slope inclination). Its two sites of observations are extended between classes $\boldsymbol{0}$ and $\mathbf{1 . 5}$. 
ii) In Foumban, the landslide sites mostly met two conditions and are surrounded by the three conditions, that is from the class coded 1.25 (Soil moisture \& Slope inclination) to the class coded 2.25 (Bare soil \& Soil moisture \& Slope inclination). Its two verification sites fall between classes 0 and 2.25, but are not concerned with the class coded 1.75. iii) In Bafoussam, the landslide site of Gouache matches the class coded 1.5 (Bare soil \& Slope inclination) and is bounded by classes coded 1.25 (Soil moisture \& Slope inclination) and 1.75 (Bare soil \& Soil moisture). Among its five verification sites, four $(2,3,4 \& 5)$ are extended between the classes coded 1.5 and 2.25 , while the remaining site (1) matches the class coded $\mathbf{I}$ (Bare soil), surrounded by classes coded $\mathbf{1 . 7 5}$ and $\mathbf{2 . 2 5}$.

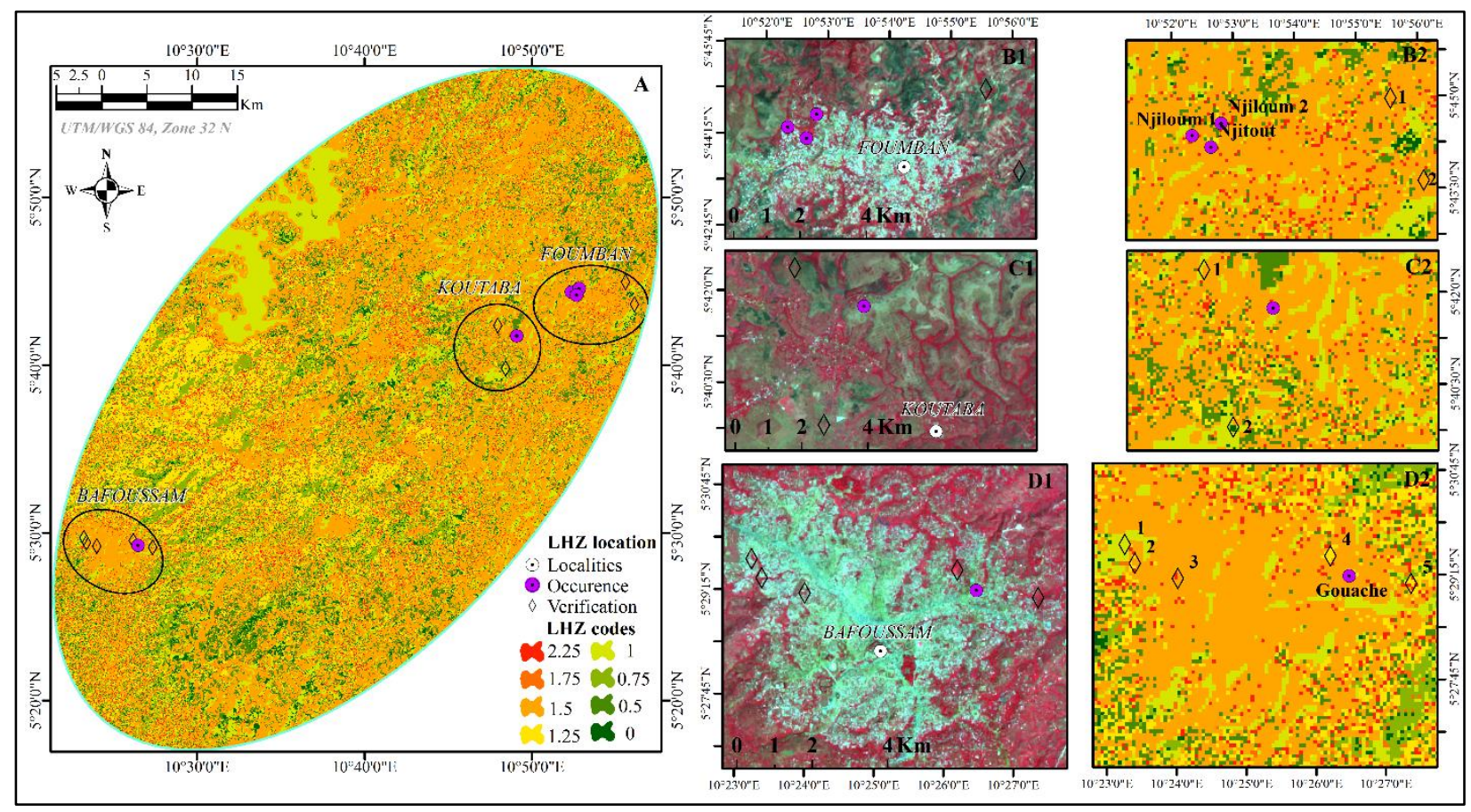

Figure 10. LHZ mapping. A) The eight classes of landslide occurrence extent and corresponding codes. B1) and B2) Patterns and sites location in Foumban. C1) and C2) Patterns and sites location in Koutaba. D1) and D2) Patterns and sites location in Bafoussam.

Statistically, the area where at least two conditions were met represents $67.5 \%$ of the study area. The largest area is occupied by the class coded 1.5 (Bare soil \& Slope inclination) with $1,709.47 \mathrm{~km}^{2}$ that represents $44 \%$ of the research area. Then follow the classes coded 1.25 (Soil moisture \& Slope inclination; $629.92 \mathrm{~km}^{2} ; 16 \%$ ), 2.25 (Bare soil \& Soil moisture \& Slope inclination; $217.75 \mathrm{~km}^{2} ; 6 \%$ ) and 1.75 (Bare soil \& Soil moisture; $69.34 \mathrm{~km}^{2} ; 2 \%$ ). The none condition class, $\boldsymbol{0}$, as well as the single conditions classes coded 0.5 (Slope inclination), 0.75 (Soil moisture) and 1 (Bare soil) cover $1,276.29 \mathrm{~km}^{2}$, representing $32.5 \%$ of the study subset (Fig.11). 

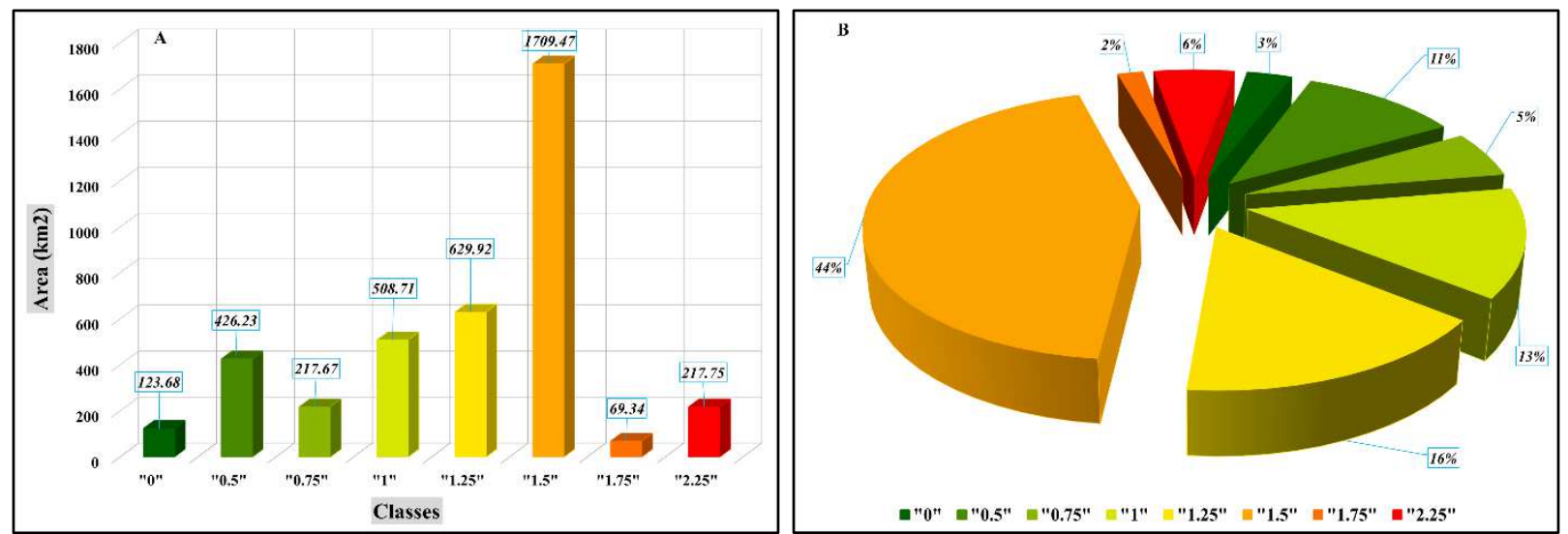

Figure 11. Areas (A) and percentages (B) of LHZ per classes.

\section{Rainfall thresholds triggering the landslides}

The highest concentration of rainfall and days of rainfall reveals information related to landslides occurrence (Fig.12).

The maps outputted from the rainfall data show how the three sites Koutaba, Foumban and Bafoussam match the main rainfall hot spots. The largest and densified spot is in the southern area, the second one is in the west and the third one is in the northeast area. At first sight and according to a visual comparison with the SLIP algorithm output, it may be assumed that rainfall concentration, in terms of quantity and number of days, is related to landslides.
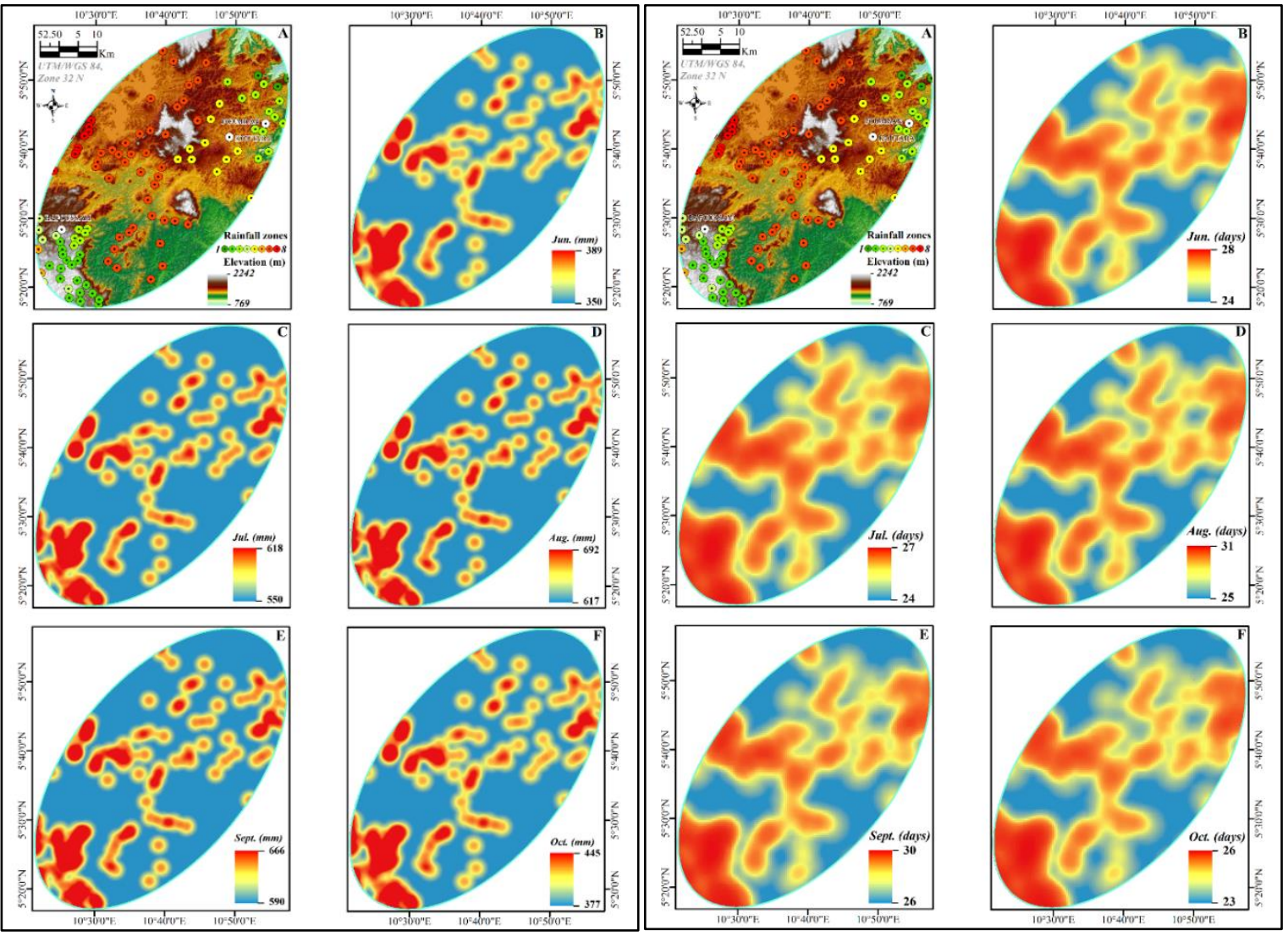

Figure 12. Spatial distribution of daily rainfall (left) and days of rainfall (right) from June to October 
The further analysis of the logistic regression helps to comfort and discuss this assumption. The prediction model of rainfall-triggered landslide thresholds is expressed as:

$$
\begin{aligned}
f(Y)=\operatorname{Exp}( & \left(-17.338+20.31 * X_{1.1 .}-0.0000000013 * X_{1.2 .}+0.0000000003 * X_{1.3 .}\right. \\
& \left.\left.+0.0000000002-10 * X_{2.2 .}-0.000000002 * X_{2.3 .}\right)\right) \div(1+\operatorname{Exp}(-(-17.338 \\
& +20.31 * X_{1.1 .}-0.0000000013 * X_{1.2 .}+0.0000000003 * X_{1.3 .}+0.0000000002-10 \\
& \left.\left.\left.* X_{2.2 .}-0.000000002 * X_{2.3 .}\right)\right)\right)
\end{aligned}
$$

\begin{tabular}{|c|c|c|}
\hline \multirow{2}{*}{ Ranges Probability } & \multicolumn{2}{|l|}{$f(Y) \leq 0.29$} \\
\hline & Expression & Landslide occurrence \\
\hline$f_{\left(X_{1}\right)} ; f_{\left(X_{2}\right)} \leq \mathbf{0 . 2 2 9}$ & $\operatorname{Exp}(-(-17.34+20.31)) / 1+\exp (-(-17.34+20.31))$ & $4.88 \%$ \\
\hline $0.229<f_{\left(X_{1}\right)}, f_{\left(X_{2}\right)} \leq 0.394$ & $\begin{aligned} \operatorname{Exp}(-(-17.34- & 0.0000000013+0.0000000002)) /(1 \\
& +\exp (-(-17.34-0.0000000013 \\
& +0.0000000002)))\end{aligned}$ & $99.99 \%$ \\
\hline$f_{\left(X_{1}\right)}, f_{\left(X_{2}\right)} \geq 0.394$ & $\begin{aligned} \operatorname{Exp}(-(-17.34+ & 0.0000000003-0.000000002)) /(1 \\
& +\exp (-(-17.34+0.0000000003 \\
& -0.000000002)))\end{aligned}$ & $99.99 \%$ \\
\hline $\begin{array}{l}f_{\left(X_{1}\right)} \leq 0.229 \\
0.229<f_{\left(X_{2}\right)} \leq 0.394\end{array}$ & $\begin{aligned} \operatorname{Exp}(-(-17.34+ & 20.31+0.0000000002)) /(1 \\
& +\exp (-(-17.34+20.31 \\
& +0.0000000002)))\end{aligned}$ & $4.88 \%$ \\
\hline $\begin{array}{l}f_{\left(X_{1}\right)} \leq 0.229 \\
f_{\left(X_{2}\right)}>0.394\end{array}$ & $\begin{aligned} \operatorname{Exp}(-(-17.34+ & 20.31-0.000000002)) /(1 \\
+ & \exp (-(-17.34+20.31-0.000000002)))\end{aligned}$ & $4.88 \%$ \\
\hline $\begin{array}{l}0.229<f_{\left(X_{1}\right)} \leq 0.394 \\
f_{\left(X_{2}\right)} \leq 0.229\end{array}$ & $\begin{aligned} \operatorname{Exp}(-(-17.34+ & 0.0000000013)) /(1 \\
& ++\exp (-(-17.34+0.0000000013)))\end{aligned}$ & $99.99 \%$ \\
\hline $\begin{array}{r}f_{\left(X_{2}\right)} \leq 0.229 \\
f_{\left(X_{1}\right)}>0.394\end{array}$ & $\begin{aligned} \operatorname{Exp}(-(-17.338+ & 0.0000000002)) /(1 \\
& +\exp (-(-17.338+0.0000000002)))\end{aligned}$ & $99.99 \%$ \\
\hline $\begin{array}{l}0.229<f_{\left(X_{1}\right)} \leq 0.394 \\
f_{\left(X_{2}\right)}>0.394\end{array}$ & $\begin{aligned} \operatorname{Exp}(-(-17.34- & 0.0000000013+0.000000002)) /(1 \\
& +\exp (-(-17.34-0.0000000013 \\
& +0.000000002)))\end{aligned}$ & $99.99 \%$ \\
\hline $\begin{array}{l}0.229<f_{\left(X_{2}\right)} \leq 0.394 \\
f_{\left(X_{1}\right)}>0.394\end{array}$ & $\begin{aligned} \operatorname{Exp}(-(-17.34+ & 0.0000000002+0.00000000035)) /(1 \\
& +\exp (-(-17.34+0.0000000002 \\
& +0.00000000035)))\end{aligned}$ & $99.99 \%$ \\
\hline
\end{tabular}

As a reminder, $\boldsymbol{X}_{\mathbf{1}}$ represents the rainfall frequency and $\boldsymbol{X}_{\mathbf{2}}$ stands for the days of rainfall frequency between 19482018, while $\boldsymbol{Y}$ is their intersection for the year 2019 (Tab.5).

Table 5. Different probabilities expressed by the prediction model.

There are six ranges of probability over nine (6/9) that are rainfall-triggered landslides event, $\boldsymbol{Y}$. The landslide probability is obvious at $99.99 \%$ when $\mathbf{0 . 2 2 9} \leq \boldsymbol{X}_{\mathbf{1}}, \boldsymbol{X}_{\mathbf{2}}<\mathbf{0 . 3 9 4}$ or $\boldsymbol{X}_{\mathbf{1}}, \boldsymbol{X}_{\mathbf{2}} \geq \mathbf{0 . 3 9 4}$. However, the influence of the 
rainfall frequency on the landslide is higher than the days of rainfall frequency, such as for $\boldsymbol{X}_{\mathbf{1}} \geq \mathbf{0 . 2 2 9}$ and $\boldsymbol{X}_{\mathbf{1}} \geq$ 0. 394, the probability remains $99.99 \%$, no matter if the rainfall frequency $\boldsymbol{X}_{\mathbf{2}}<\mathbf{0 . 2 2 9}$. Reversely, for all rainfall frequency $\boldsymbol{X}_{\mathbf{1}} \leq \mathbf{0 . 2 2 9}$, the probability of landslide occurrence is very low, $4.88 \%$, no matter if for the days of rainfall frequency, $0.229<X_{2} \leq \mathbf{0 . 3 9 4}$ or $X_{2} \geq \mathbf{0 . 3 9 4}$. Consequently, the frequency of rainfall alone is able to trigger a landslide event in the study area once the minimum threshold of 0.229 is reached. Therefore, the adapted DRIP approach shows suitability to distinguish landslide and no-landslide for one common frequency.

\section{Lifetime of sites to rainfall-triggered landslide}

Applying the Cobbs-Douglas formula, the following models were withdrawn from the analysis of variance, ANOVA, regressions on the five sites of landslides occurrence (Tab.6).

Table 6. Equations of ANOVA regression for the observed sites.

\begin{tabular}{|c|c|c|}
\hline Observed sites (Period) & Model & Values \\
\hline S1-Njiloum1 (1948-2018) & $0.03004 * 18119.1 * 607^{2.012 *(-0.488)}$ & 1.0073 \\
\hline S2-Njiloum2 (1948-2018) & $0.03004 * 33858 * 607^{2.012 *(-0.2612)}$ & 35.0509529712193 \\
\hline S3-Njitout (1948-2018) & $0.03004 * 158816.73 * 607^{2.012 *(-0.394)}$ & 29.6676110831837 \\
\hline S4-Koutaba (1948-2018) & $0.0305 * 1812 * 610^{1.694 *(-0.493)}$ & 0.260802712270763 \\
\hline S5-Bafoussam (1948-2018) & $0.0233 * 13589.52 * 613^{1.76 *(-0.3463)}$ & 6.33339140678556 \\
\hline Mean 1948-2018 & & 14.4640116346919 \\
\hline S1-Njiloum1 (2019) & $18255.1 * 55603585 * 614^{1.1724 *(-0.886)}$ & 1878436394.94023 \\
\hline S2-Njiloum2 (2019) & $18255.1 * 58869398061659300 * 614^{1.1724 *(-1.473)}$ & 16453557989053200 \\
\hline S3-Njitout (2019) & $18255.04 * 309547810768.523 * 614^{1.1724 *(-1.13)}$ & 1143698653144.39 \\
\hline S4- Koutaba (2019) & $18255.04 * 55603585 * 616^{1.63 *(-0.903)}$ & 79529751.9255277 \\
\hline S5-Bafoussam (2019) & $13691.28 * 41702688.98 * 618^{1.94 *(-0.646)}$ & 181480394.584158 \\
\hline Mean 2019 & & 3290940765430580 \\
\hline
\end{tabular}

These values were normalized by dividing each site $\boldsymbol{S}_{\boldsymbol{i}}$ value by the mean of all values for each period. Then after, the most recurrent interval between LHZ codes, $\boldsymbol{0 . 2 5}$, was used to increment or decrement the normalized values towards the closest map class. Further, the means of the originally normalized values (Tab.7) were computed for each $\boldsymbol{S}_{\boldsymbol{i}}$, giving ten values for the study period 1948-2019. These means vary between 0.009 (Koutaba) and 3.7 (Njiloum2Foumban) and served as coefficients for the kriging process to predict the verification sites $\boldsymbol{S}_{\mathbf{0}}$ (Tab.7). In addition, the nine verification sites $\boldsymbol{S}_{\mathbf{0}}$ were coupled in four dependent variables for the linear regression with the known sites $\boldsymbol{S}_{\boldsymbol{i}}$, and their LHZ codes were ordered in ten value enhancing the variability, such as: $i$ ) Foumban: verification sites 1 and $2=\boldsymbol{S}_{\mathbf{0}}$-Foumban; ii) Koutaba: verification sites 1 and $2=\boldsymbol{S}_{\mathbf{0}}$-Koutaba; iii) Bafoussam: verification 1 and $2=\boldsymbol{S}_{\mathbf{0}}$ Bafoussam1, verification 3, 4 and 5= $\boldsymbol{S}_{\mathbf{0}}$-Bafoussam2. (Tab.8). Table 9 gives the four detailed kriging models for each $S_{0}$ as well as the results. With respectively 1.99 and $1.642, S_{0}$-Bafoussam1 and $S_{0}$-Bafoussam 2 are the highly exposed sites to a potential rainfall-triggered landslide. $\boldsymbol{S}_{\mathbf{0}}$-Foumban records the third value, $\mathbf{1 . 0 6}$, while $\boldsymbol{S}_{\mathbf{0}}$-Koutaba, shows the negative value $-\mathbf{8 5 7 1}$. 
Table 7. Normalized and incremented/decremented coefficients.

\begin{tabular}{|c|c|c|c|c|c|c|}
\hline \multirow[t]{2}{*}{ Years } & \multirow{2}{*}{$\begin{array}{l}\text { Coefficient } \\
\text { status }\end{array}$} & \multicolumn{5}{|c|}{ Observed sites } \\
\hline & & S1-Njiloum1 & S2-Njiloum2 & S3-Njitout & S4-Koutaba & S5-Bafoussam \\
\hline \multirow{5}{*}{ 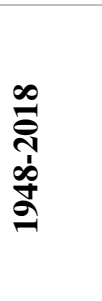 } & Normalized & 0.0696 & 2.423 & 2.051 & 0.01803 & 0.4378 \\
\hline & \multirow{4}{*}{$\begin{array}{l}\text { Incremented / } \\
\text { Decremented at } \\
\text { a pace of } 0.25\end{array}$} & 0.319 & 2.173 & 1.801 & 0.26803 & 0.6878 \\
\hline & & 0.569 & 1.923 & 1.551 & 0.51803 & 0.9378 \\
\hline & & 0.819 & 1.673 & 1.301 & 0.76803 & 1.1878 \\
\hline & & 1.696 & 1.423 & 1.051 & 1.01803 & 1.4378 \\
\hline \multirow{5}{*}{ 궁 } & Normalized & 0.00000057 & 4.999 & 0.000347 & 0.000000024 & 0.00000006 \\
\hline & \multirow{4}{*}{$\begin{array}{l}\text { Incremented } \\
\text { Decremented at } \\
\text { a pace of } 0.25\end{array}$} & 0.25000057 & 4.749 & 0.250347 & 0.250000024 & 0.25000006 \\
\hline & & 0.50000057 & 4.499 & 0.500347 & 0.500000024 & 0.50000006 \\
\hline & & 0.75000057 & 4.249 & 0.750347 & 0.750000024 & 0.75000006 \\
\hline & & 1.00000057 & 3.999 & 1.000347 & 1.000000024 & 1.00000006 \\
\hline \multicolumn{2}{|c|}{$\mu$ of normalized values } & 0.0348 & 3.7114 & 1.0257 & 0.009 & 0.2189 \\
\hline
\end{tabular}

Table 8. LHZ codes matching and surrounding the verification sites.

\begin{tabular}{|c|c|c|}
\hline Sites & Corresponding LHZ codes & $S_{0}$ selected codes \\
\hline Koutaba-Verification 1 & $0.01 * ; 0.5 ; 0.75 ; 1 ; 1.5$ & \multirow[t]{2}{*}{$0.01 * ; 0.01 ; 0.5 ; 0.5 ; 0.75 ; 0.75 ; 1 ; 1 ; 1.25 ; 1.5$} \\
\hline Koutaba-Verification 2 & $0.01 ; 0.5 ; 0.75 ; 1 ; 1.25$ & \\
\hline Foumban-Verification 1 & $0.01 ; 0.75 ; 1 ; 1.25 ; 1.5$ & \multirow[t]{2}{*}{$0.01 ; 0.5 ; 0.75 ; 0.75 ; 1 ; 1 ; 1.25 ; 1.5 ; 1.5 ; 2.25$} \\
\hline Foumban-Verification 2 & $0.5 ; 0.75 ; 1 ; 1.5 ; 2.25$ & \\
\hline Bafoussam-Verification 1 & $0.75 ; 1 ; 1.25 ; 1.5 ; 2.25$ & \multirow[t]{2}{*}{$0.01 ; 0.5 ; 0.5 ; 0.75 ; 1 ; 1 ; 1.25 ; 1.5 ; 1.5 ; 2.25$} \\
\hline Bafoussam-Verification 2 & $0.01 ; 0.5 ; 1 ; 1.25 ; 1.5$ & \\
\hline Bafoussam-Verification 3 & $0.5 ; 0.75 ; 1 ; 1.5 ; 2.25$ & \multirow{3}{*}{$0.01 ; 0.5 ; 1 ; 1 ; 1.25 ; 1.25 ; 1.5 ; 1.75 ; 2.25 ; 2.25$} \\
\hline Bafoussam-Verification 4 & $1 ; 1.25 ; 1.5 ; 1.75 ; 2.25$ & \\
\hline Bafoussam-Verification 5 & $0.01 ; 0.75 ; 1 ; 1.25 ; 2.25$ & \\
\hline
\end{tabular}

* Used to replace $L H Z$ code $\mathbf{0}$, assuming that each class influences the modelling at some point.

Table 9. Observed sites kriging equations and results.

\begin{tabular}{|l|r|r|}
\hline Observed sites & Model & Values \\
\hline $\boldsymbol{S}_{\mathbf{0}}$-Foumban & $-2.239 * 0.0348+0.026 * 3.711+0.485 * 1.026$ & $\mathbf{1 . 0 6}$ \\
& $+0.001 * 0.009+2.468 * 0.219$ & \\
\hline $\boldsymbol{S}_{\mathbf{0}}$-Koutaba & $\begin{array}{r}1.863 * 0.0348-0.134 * 3.711-0.59 * 1.026+0.001 \\
\end{array}$ & $\mathbf{- 0 . 8 5 7 1}$ \\
\hline $\boldsymbol{S}_{\mathbf{0}}$-Bafoussam1 & $-2.988 * 0.0348+0.104 * 3.711+1.321 * 1.026$ & $\mathbf{1 . 9 9 6}$ \\
& $+0.001 * 0.009+1.637 * 0.219$ & \\
\hline $\boldsymbol{S}_{\mathbf{0}}$-Bafoussam2 & $-1.507 * 0.0348+0.093 * 3.711+1.244 * 1.026$ & $\mathbf{1 . 6 4 2}$ \\
& $+0.001 * 0.009+0.333 * 0.219$ & \\
\hline
\end{tabular}

Further, based on the landslide occurrence dates, the following parameters were introduced in the Cox model computation. (Tab.10) 
Table 10. The Cox model parameters.

\begin{tabular}{|l|l|l|l|l|l|l|}
\hline & Start date & End date & Point date & Time (days) & Censored status & Covariate \\
\hline S1-Njiloum1 & $1 / 1 / 1954$ & $4 / 9 / 2018$ & $1 / 8 / 2018$ & 23,379 & 1 & 0.0348 \\
\hline S2-Njiloum2 & $1 / 1 / 1954$ & $4 / 9 / 2018$ & $1 / 8 / 2018$ & 23,379 & 1 & 3.7114 \\
\hline S3-Njitout & $1 / 1 / 1954$ & $5 / 9 / 2018$ & $1 / 8 / 2018$ & 23,380 & 1 & 1.0257 \\
\hline S4-Koutaba & $1 / 1 / 1954$ & $23 / 10 / 2011$ & $1 / 8 / 2018$ & 20,871 & 0 & 0.009 \\
\hline S5-Gouache & $1 / 1 / 1954$ & $29 / 9 / 2019$ & $1 / 8 / 2018$ & 23,799 & 1 & 0.2189 \\
\hline
\end{tabular}

The ' start date' corresponds to the first landslide archived in Cameroon. The 'end date' is the landslide occurrence events on the site. The ' point date' is based on the analyst observations of the phenomenon, and in this case, it was defined according to the peak of rainfall starting in August, as well as on the highest percentage of landslide's occurrence that are 22\% in August, $45 \%$ in September and 21\% in October (See tabl.2). The elapsed time was estimated in days rounded to the upper bound unit. The ' censored status' is 1 for the failure to survive, that is the occurrence after the ' point date ' and 0 for success, i.e., the success or no-failure to survive before the ' point date'.

From the results presented in figure 14a, the survival probability of a site to rainfall-triggered landslide under 23,300 days of age was $\approx \mathbf{0 . 6 8}$ (68\%), and the site $\mathbf{S 4 - K o u t a b a}$ is the only concerned in this category. Between approximately 23,370 days and 23,700 days of ages, this probability was $\approx \mathbf{0 . 3 8}(\mathbf{3 8 \%})$. The three sites S1-Njiloum1, S2-Njiloum $\mathbf{2}$ and S3-Njitout in Foumban, belong to this interval. Above 23,700 days of age, the survival probability keeps decreasing between $\approx 0.38$ and $\approx 0.1(10 \%)$. The only site that matches this category is S5-Gouache in Bafoussam. Inversely, and based on figure 14b, the rainfall-triggered landslides hazard increases with time. Technically then, the exposure of S5-Bafoussam to that hazard is higher than the other sites, while the lowest exposure is at S4- Koutaba. The hazard ratio is $\mathbf{1 . 4 7 4 \approx 1 . 5}$. (tab.11), corresponding to the time-to-event, meaning that at any time, one-and-half as many sites of occurrence (i.e., $\mathbf{1 . 5} * \mathbf{5}=\mathbf{7 . 5}$ ) are exposed to landslides.

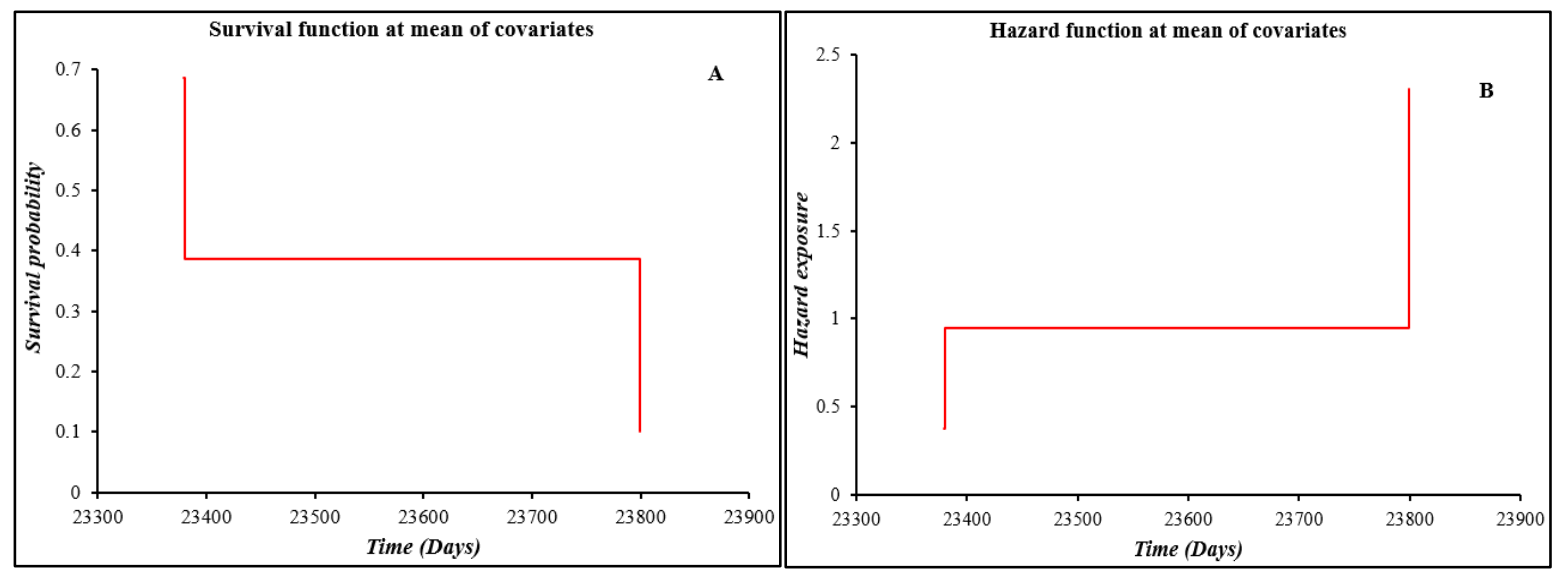

Figure 14. Survival probability (A) and hazard exposure (B) of the five landslide occurrence sites.

Table11. Summary statistics.

\begin{tabular}{|l|l|l|l|l|l|}
\hline Total observed & Total failed & Total censored & Time steps & Covariates coefficient $(\beta)$ & Hazard ratio \\
\hline $\mathbf{5}$ & $\mathbf{4}$ & $\mathbf{1}$ & $\mathbf{4}$ & $\mathbf{0 . 3 8 8}$ & $\mathbf{1 . 4 7 4}$ \\
\hline
\end{tabular}


The results above commented and their beta coefficients, $\boldsymbol{\beta}=\mathbf{0 . 3 8 8}$, were used to elaborate Cox proportional hazards model for the four unknown sites, $\boldsymbol{S}_{\mathbf{0}}$. Their hazard ratio instantaneous risk was computed using the models detailed in table 12 below.

Table 12. Hazard ratios instantaneous risk models for the observed sites.

\begin{tabular}{|l|c|l|}
\hline Observed sites & Model & Values \\
\hline $\boldsymbol{S}_{\mathbf{0}}$-Foumban & $\exp (0.388 * 1.06) / \exp (0.388 * 1)$ & $\mathbf{1 . 0 2}$ \\
\hline $\boldsymbol{S}_{\mathbf{0}}$-Koutaba & $\exp (0.388 *(-0.8571) / \exp (0.388 * 1)$ & $\mathbf{0 . 4 9}$ \\
\hline $\boldsymbol{S}_{\mathbf{0}}$-Bafoussam1 & $\exp (0.388 * 1.996) / \exp (0.388 * 1)$ & $\mathbf{1 . 4 7}$ \\
\hline $\boldsymbol{S}_{\mathbf{0}}$-Bafoussam2 & $\exp (0.388 * 1.642) / \exp (0.388 * 1)$ & $\mathbf{1 . 2 8}$ \\
\hline
\end{tabular}

The highest ratio is observed at $S_{0}$-Bafoussaml with 1.47 that is almost as same as the hazard ratio. The other sites in the decreasing order are $S_{0}$-Bafoussam2, $S_{0}$-Foumban and $S_{0}$-Koutaba, with respectively 1.28, 1.02 and 0.49.

\section{Discussions and conclusions}

The two algorithms of SLIP and DRIP such as originally developed (Fayne et al., 2018) and adapted in this research connect landslides occurrence and huge rainfall. The interest has been to adjust the process to gaps in data, precisely the discontinuity among satellite images due to cloud cover and the unavailability of rainfall data at an hourly pace. According to the SLIP processing, the highly exposed class to landslide occurrence meets the three conditions of bare soil, soil moisture and slope inclination thresholds, i.e., the LHZ code 2.25. Based on their location, five landslide sites match or are surrounded by this class, confirming the efficiency of the mapping method. In addition, five out of nine (5/9) verification sites support this statement, and give with the five previous a total match up to $71 \%$ (10/14 sites). However, these accuracies are affected by the satellite images season, because the areas calculated may be $x$ time more or less referring to the appending processing applied to approximate vegetation/no-vegetation area between the dry and the rainy season (Appendix 2). In addition, the built-up extent and material can introduce biases especially when computing soil spectral indices (Ngandam et al., 2019). For instance, cities as Bafoussam and Foumban are characterized by their mi-rural/mid-urban patterns that include many houses in raw material such as earthen bricks and straw roofs, or unpaved dusty/muddy roads and tracks. Therefore, their reflectance may create mixed-pixel in the INDVI result, because they usually reflect enough in the red and SWIR wavelengths of Landsat 8 images just as the landslide-affected areas (Ngandam et al., 2019).

Further, the DRIP modelling accuracy assessment holds in two approaches. The first is the confusion matrix, extracted from the logistic regression's classification table, based on the true positive rate, $T P R$, defining the ratio of all positive cases correctly predicted, and the false positive rate, $F P R$, expressing the ratio of all negative cases that are incorrectly predicted to be positive, under a defined threshold value. They are formulated as follows:

$$
\begin{aligned}
\text { i) } \mathbf{T P R} & =\mathbf{T P} /(\mathbf{T P}+\mathbf{F N}) \\
\text { ii) } \mathbf{F P R} & =\mathbf{F P} /(\mathbf{F P}+\mathbf{T N})
\end{aligned}
$$

With 50 observations of rainfall in the 10 zones, the TPR or sensitivity at is up to $100 \%$ (39/39), while the FPR or specificity is $82 \%$ (Tab.13). Both give an overall accuracy of $96 \%$, corresponding to the rate of rainfall and days of rainfall frequencies equal or beyond thresholds triggering the landslides. 
Table 13. Classification table for the training sample - variable $Y_{1}$.

\begin{tabular}{|l|l|l|l|c|}
\hline \multicolumn{1}{|c|}{ Calculated } & 0 & 1 & Total & \% Correct \\
\hline 0 & & & & \\
\hline 1 & 9 & 2 & 11 & $\mathbf{8 1 . 8 2}$ \\
\hline Total & 0 & 39 & 39 & $\mathbf{1 0 0}$ \\
\hline
\end{tabular}

In addition, the positive predictive value, PPV, and the negative predictive value, NPV, that are respectively the proportions of positive and negative results were computed. They are expressed as follows:

$$
\begin{aligned}
& \text { i) } \mathbf{P P V}=\mathbf{N T P} /(\mathbf{N T P}+\mathbf{N T N}) \\
& \text { ii) } \mathbf{N P V}=\mathbf{N F P} /(\mathbf{N F P}+\mathbf{N F N})
\end{aligned}
$$

From the data of table 13 above, the PPV is $\mathbf{9 5 \%}$ (39/41) while reversely, the NPV is 5\% (2/41). These are high accuracies of the efficiency of a post-landslide analysis in relation with a daily rainfall, to potentially know a date of occurrence. However, the unavailability of hourly rainfall to proceed to a timing limits to properly correlate the two data frequency.

On the last step dedicated to the survival analysis of sites, the goal was to predict and correlate daily rainfall, days of rainfall and the magnitude of the landslide in terms of speed of occurrence, to complete the status mapping and timely retrospective of the original algorithms. Based on the rainfall intensity deducted on a daily pace, the processing was able to perform a lifetime analysis, departing from the first event archived in Cameroon on $1 / 1 / 1954$, for the known and unknown sites. The survival probability of affected sites decreases with time, while the hazard of rainfall-triggered landslide increases. The unknown sites Cox's proportional hazards model can then be applied to the other sites of Cameroon, where rainfall data are available and landslides historic are archived. However, the huge rainfall of 81 millimeters in $\approx 36$ hours preceding the landslide of Bafoussam-Gouache was not especially integrated in the processing, what raises the interrogation on the accurate timing as well as the rainfall intensity threshold to be used in the model.

To sum up, although the accuracies suffer potential drawbacks and caveats, the proposed methodology contributes to another vision of the SLIP and DRIP algorithms. It offers a new alternative in case of voids and gaps between data, as well as the complementary step of survival analysis.

\section{Acknowledgements}

In memory of the 45 deaths and dozens of other victims (injured, homeless) reported for the 29 October 2019 landslide event in Bafoussam. In support of Cameroons' government, NGOs and civil groups actions to predict geohazards occurrence as well as mitigate their impact. The authors are grateful to the reviewers whose remarks and suggestions were fundamental to the improvement of the manuscript.

\section{Authors' contributions}

The first two authors conceived, carried out the research and mapping, drafted the manuscript and finalized the corrections. The first and the third authors directed and validated the statistical process and modelling. The whole team contributed to fieldwork, data collection and curation, method validation, literature sourcing, mapping, editing, structuring and critical reviewing. All the authors read and approved the final manuscript. 


\section{Funding}

The private consulting firm StatsN'Maps, through its 'Research Support Funds' (SN'M-RSF), financially supported the purchase of articles and books chapters not free, as well as all the fieldwork investigations concerning rainfall data acquisition. The licenses of Erdas Imagine 2020 version 16.6.0.1366, ArcGisPro version 2.5 and XLStats 2020.1.64570 software used in this research are properties of StatsN'Maps and available upon request.

\section{Availability of data and materials}

All the data and material used for this research were incorporated as needed to the text or added as appendixes. For all other details needed, contact the corresponding author via the following email: stats.n.maps.expertise@gmail.com.

\section{Competing interests}

The authors declare that they have no competing interests.

\section{References}

Ada, M, San, BT, (2018) Comparison of machine-learning techniques for landslide susceptibility mapping using twolevel random sampling (2LRS) in Alakir Catchment area, Antalya, Turkey. Nat. Hazards, 90, 237-263

Ayonghe SN, Suh CE, Ntasin EB, Samalang P \& Fantong W (2002) Hydrologcally, seismically and tectonically triggered landslides along the Cameroon Volcanic Line, Cameroon. Africa Geosciences Review, 9:4, 325-335.

Balla A., Kagou Dongmo, A., Nkouathio, D. G. and Ngapgue F (2013) Land instability in the highlands of western Cameroon: geological and geotechnical characterization of the Kekem landslide. Bulletin de l'Institut Scientifique, Rabat, Section Sciences de la Terre, 35, 39-51.

Baudains, P; Zamazalová, S; Altaweel, M; Wilson, A; (2015) Modeling Strategic Decisions in the Formation of the Early Neo-Assyrian Empire. Cliodynamics: The Journal of Quantitative History and Cultural Evolution, 6 (1), 1 -23 Blahut, J, VanWesten, C, Sterlacchini, S (2010) Analysis of landslide inventories for accurate prediction of debrisflow source areas. Geophys J Roy Astron Soc., 119:36-51.

Brabb, E (1993) Proposal for worldwide landslide hazard maps. In: Novosad, S \& Wagner, P (eds.) Proceedings of the 7th International Conference and Workshop on Landslides. Balkema, AACzech and Slovak Republics, 15-27.

Braun, SA (2011) "TRMM Status," $7^{\text {th }}$ GPM International Planning Workshop, Tokyo, Japan, Dec. 5-7. URL: http://www.eorc.jaxa.jp/GPM/ws7/pdf/5thDEC2007/AM/5_am06.pdf

Brusden, D (1984) Mudslides. In: Brusden, D, Prior, D, editors. Slope Instability. Chichester: Wiley, pp. $363-418$.

Bui, D, Pradhan, B, Lofman, O, Dick, O (2012) Landslide susceptibility assessment in the Hoa Binh Province of Vietnam: a comparison of the Levenberg-Marquardt and Bayesian regularized neural networks. Geophys J Roy Astron. Soc., 171-172:12-29.

Calvello M, Cascini L, Mastroianni S (2013) Landslide zoning over large areas from a sample inventory by means of scale-dependant terrain units. Geophys J Roy Astron Soc., 182:33-48.

Canavesi, V, Segoni, S, Rosi, A, Ting, X, Nery, T, Catani, F, Casagli, N. (2020) Different Approaches to Use Morphometric Attributes in Landslide Susceptibility Mapping Based on Meso-Scale Spatial Units: A Case Study in Rio de Janeiro (Brazil). Remote Sens., 12, 1826.

Colombo, A, Lanteri, L., Ramasco, M. and Troisi, C. (2005) Systematic GIS-based landslide inventory as the first step for effective landslide-hazard management. Landslides 2:4, 291-301. 
Couture, R (2011) Landslide Terminology - National Technical Guidelines and Best Practices on Landslides. Geological Survey of Canada, Open File 6824, 12 p.

Cox, DR (1972) Regression models and Life-Tables. Journal of the Royal Statistical Society, 34(2), 187-220.

Crozier, MJ (1986): Landslides: Causes, Consequences and Environment. London and Sidney, Croom Helm Limited, $252 \mathrm{p}$.

Cruden, DM (1991) A simple definition of landslide. Bulletin of international association of Engineering Geology, 43:1, 27-29.

Cruden, DM and Varnes, DJ (1996) Landslide types and processes. Transportation Research Board, U.S. National Academy of Sciences, Special Report, 247:36-75

Cyr, D, Gauthier, S, and Bergeron, Y. (2007). Scale-dependent determinants of heterogeneity in fire frequency in a coniferous boreal forest of eastern Canada. Landscape Ecology, 22(9), 1325-1339.

Dezfuli, AK, Ichoku, CM, Mohr, KI and Huffman, GJ (2017) Precipitation characteristics in West and East Africa from satellite and in situ observations. Journ. of Hydrometeo., 18:6, 1799-1805.

Djouka F.M.L., Schulz B., Schüssler U., Tchouankoue J.P. and Nzolang C. 2008. Geochemistry of the Bafoussam Pan-African I- and S-type granitoids in western Cameroon. Journ. of Afric. Ear. Sci., 50, 148-167.

Elsheikh, AA, Gao, SS, Liu, KH (2014) Formation of the Cameroon Volcanic Line by lithospheric basal erosion: Insight from mantle seismic anisotropy. Journal of African Earth Sciences, 100: 96-108.

Erdas Imagine (2008) Imagine DeltaCue user's guide. ERDAS INC., p 128.

http://faculty.une.edu/cas/szeeman/rs/docs/DeltaCue.pdf

Fayne, JV, Ahamed, A, Roberts-Pierel, J, Rumsey, AC, Kirschbaum, DB (2019) Automated Satellite-Based Landslide Identification Product for Nepal. Earth Interactions, 23:3, p.23.

Galli, M, Ardizzone, F, Cardinali, M, Guzzetti, F, Reichenbach, P (2008) Comparing landslide inventory maps. Geomorphology, 94:268-289.

Garosi, Y, Sheklabadi, M, Pourghasemi, HR, Besalatpour, AA, Conoscenti, C., Oost, KV (2018) Comparison of differences in resolution and sources of controlling factors for gully erosion susceptibility mapping. Geoderma 330: 65-78.

Goetz, J, Brenning, A, Petschko, H, Leopold, P (2015) Evaluating machine learning and statistical prediction techniques for landslide susceptibility modeling. Comput. Geosci., 81, 1-11.

Gosh, K, Bandyopadhyay, S, Kumar De, S (2011) A Comparative Evaluation of Weight-Rating and Analytical Hierarchical (AHP) for Landslide Susceptibility Mapping in Dhalai District, Tripura. Environment and Earth Journal Observation, pp. 175-193.

Guzzetti, F, Reichenbach, P, Cardinali, M, Galli, M and Ardizzone, F (2005) Probabilistic landslide hazard assessment at the basin scale. Geomorphology 72: 272-299.

Guzzetti, F, Carrara, A, Cardinali, M, Reichenbach, P (1999) Landslide hazard evaluation: a review of current techniques and their application in a multi-scale study, Central Italy. Geomorphology, 31:181-216. 
Hutchinson, JN (1988) General Report: Morphological and geotechnical parameters of landslides in relation to geology and hydrogeology. Proceedings, Fifth International Symposium on Landslides, Rotterdam: Balkema, (Ed: Bonnard, C.), 1:3-35.

Institute of Geological and Mining Research (IGMR)-Penaye, J, Ateba, B, Wokwenmendam Nguet, P, Moudioh, C (2018) Disaster of September 2018 in the Njintout and Njiloum districts of Foumban. Scientific opinion. Translated from French original version. Field mission report, 15p.

Institute of Geological and Mining Research (IGMR)-Kankeu B \& Ntchantcho R (2019) Natural disasters in GouacheBafoussam, scientific causes. Translated from French original version. Filed mission report, Report,14 p.

Jiménez-Perálvarez, JD, Irigaray, C, El Hamdouni, R, and Chacón, J (2011) Landslide-susceptibility mapping in a semi-arid mountain environment: An example from the southern slopes of Sierra Nevada (Granada, Spain). Bull. Eng. Geol. Environ., 70:265-277.

Kanungo, DP, Arora, MK, Sarkar, S, Gupta, RP (2006) A comparative study of conventional, ANN black box, fuzzy and combined neural and fuzzy weighting procedures for landslide susceptibility zonation in Darjeeling Himalayas. Eng. Geol, 85:3-4, 347-366.

Kanungo, D, Arrora, M, Sarkar, S, Gupta, R (2009) Landslide Susceptibility Zonation (LSZ) mapping-a review. J South Asia Disaster Stud, 2:81-105.

Kayastha P, Dhital M. De Smedt F (2013) Application of the analytical hierarchy process (AHP) for landslide susceptibility mapping: a case study from the Tinau watershed, west Nepal. Comput Geosci 52:398-408.

Kirschbaum, DB, Adler, R, Hong, Y, Lerner-Lam, Al (2009) Evaluation of a satellite-based landslide algorithm using global landslide inventories. Nat. Hazards Earth System Sci, 9:673-686.

Klein, CA (2009) Characteristic strength, Weibull modulus, and failure probability of fused silica glass. Optical Engineering, 48, 113401.

Komac, M (2006) A landslide susceptibility model using the Analytical Hierarchy Process method and multivariate statistics in perialpine Slovenia. Geomorphology 74:1, 17-28.

Lee, S (2005) Application of logistic regression model and its validation for landslide susceptibility mapping using GIS and remote sensing data. Int. J. Remote Sens., 7:1477-1491.

Lee, C, Huang, C, Lee, J, Pan, K, Lin, M, Dong, J (2008) Statistical approach to storm event-induced landslides susceptibility. Nat Hazards Earth Syst Sci., 8:941-960.

Lin, L, Lin, Q, and Wang, Y (2017) Landslide susceptibility mapping on a global scale using the method of logistic regression. Nat. Hazards Earth Syst. Sci., 17, 1411-1424. https://doi.org/10.5194/nhess-17-1411.

Maidment, RI, Grimes, D, Allan, RP, Tarnavsky, E, Stringer, M, Hewison, T, Roebeling, R and Black, E (2014) The 30 years TAMSAT African rainfall climatology and time series (TARCAT) dataset. Journal of Geophysical Research: Atmospheres, 119:18, 10619-10644.

Marjanovi'c, M, Kova`cevi'c, M, Bajat, B, Voženílek, V (2011) Landslide susceptibility assessment using SVM machine learning algorithm. Eng. Geol., 123, 225-234

Martha T, vanWesten C, Kerle N, Jetten V, Vinod Kumar K (2013) Landslide hazard and risk assessment using semiautomatically created landslide inventories. Geophys J. Roy Astron Soc. 184:139-150. 
Meena, SR, Ghorbanzadeh, O, Blaschke, T (2019) A Comparative Study of Statistics-Based Landslide Susceptibility Models: A Case Study of the Region Affected by the Gorkha Earthquake in Nepal. Int. J. Geo-Inf. 8, 94 Moundi, A, Wandji, P, Bardintzeff, J-M, Ménard, J-J, Atouba Okomo, LC, Mouncherou, OF, Reusser, E, Bellon, H, Tchoua, FM (2007) Les basaltes éocènes à affinité transitionnelle du plateau Bamoun, témoins d'un réservoir mantellique enrichi sous la Ligne Volcanique du Cameroun. Comptes Rendus Geosciences, 339, 396-406.

Moundi, A, Konfor Njilah, I, Ghogomou Tanwi, R, and Wokwenmendam Nguet, P (2008) New Geochronological Data for the Continental Alkaline Flood Basalts of the Bamoun Plateau (West Cameroon): Evidence for an Early Alkaline Volcanism of the Cameroon Volcanic Line. Disast, Adv., 1(3), 27-33.

Ngongang N.B. Kamgang P., Chazot G. Agranier A., Bellon B., Nonnotte P. (2015) Age, geochemical characteristics and petrogenesis of Cenozoic intraplate alkaline volcanic rocks in the Bafang region, West Cameroon. Journ. of Afric. Ear. Sci., 102, 218-232.

Ngandam Mfondoum, AH, Gbetkom, PG, Wokwenmendam Nguet, P, Cooper, R, Hakdaoui, S (2019) Assessing the spatial metabolism of a mid-urban/mid-rural city: the relationship built-up, vegetation, bare soil and urban heat in Foumban (west-Cameroon, Central Africa) - periods 1987 - 2003 - 2019. Third International Land Use Symposium, ILUS, 2019 - "Land use changes: trends and projections", Paris, 4-6 December, Poster. URL: $\underline{10.13140 / R G .2 .2 .13421 .33766}$

Njilah, IK (1991) Geochemistry and Petrogenesis of Tertiary-Quaternary volcanic rocks from Oku-Ndu area, N.W. Cameroon. Ph.D. Thesis, University of Leeds, 350.

Njonfang, E., Moreau C., Tchoua, FM (1998) La bande mylonitique Foumban-Bankim, Ouest Cameroun. Une zone de cisaillement de haute température. Comptes Rendus de l'Académie des Sciences, 327, 735-741.

Pardeshi, SD, Autade, SE, and Pardeshi, SD (2013) Landslide hazard assessment: recent trends and techniques. Springer Plus, 2013, 2:523.

Petley, D (2012) Global patterns of loss of life from landslides. Geology, 40:927-930.

Pham, B.T, Pradhan, B, Bui, D.T, Prakash, I, Dholakia, M, (2016a) A comparative study of different machine learning methods for landslide susceptibility assessment: A case study of Uttarakhand area (India). Environ. Model. Softw. 84, 240-250

Pham, B.T, Bui, D.T, Prakash, I, Dholakia, M. (2016b) Rotation forest fuzzy rule-based classifier ensemble for spatial prediction of landslides using GIS. Nat. Hazards, 83, 97-127

Pham, B.T, Prakash, I, Bui, D.T. (2018) Spatial prediction of landslides using a hybrid machine learning approach based on random subspace and classification and regression trees. Geomorphology, 303, 256-270

Pradhan, B, Lee, S (2009) Landslide risk analysis using artificial neural network model focusing on different training sites. Int J Phys Sci., 4:001-015.

Preuth, T, Glade, T, Demoulin, A (2010) Stability analysis of human-influenced landslides in eastern Belgium. Geomorphology 120:38-47.

Sarkar, S, Kanungo, D, Patra, A, Kumar, P (2006) Disaster mitigation of debris flows, slope failures and landslides. GIS based landslide susceptibility mapping- a case study in Indian Himalaya. Tokyo, Japan: Universal Academy Press, pp. 617-624. 
Shirzadi, A, Soliamani, K, Habibnejhad, M, Kavian, A, Chapi, K, Shahabi, H, Chen, W, Khosravi, K, Thai Pham, B, Pradhan, B, Ahmad, A, Bin Ahmad, B, Tien Bui, D, (2018) Novel GIS Based Machine Learning Algorithms for Shallow Landslide Susceptibility Mapping. Sensors, 18, 3777.

Singh, C, Behra, K, Rocky, W (2011) Landslide susceptibility along NH-39 between Karong and Mao, Senapati District, Manipur. J Geological Soc India, 78:559-570.

Tchindjang, M, (2012) Paradoxes and risks in Cameroons' highlands: natural multifonctionality and human undervaluation. Translated from French original version. HDR, Vol. 3, University of Paris 7, 266p.

Tchindjang, M, (2013) Mapping of natural hazards in Cameroon. International Cartographic Association. URL: https://icaci.org/files/documents/ICC.../403 proceeding.pdf

Tofani, V, Segoni, S, Agostini, A, Catani, F, and Casagli, N (2013) Technical Note: Use of remote sensing for landslide studies in Europe. Nat. Hazards Earth Syst. Sci., 13:299-309.

United Nation Office for Disaster Risk Reduction -UNISDR (2017) UNISDR'S contribution to science and technology for disaster rick reduction and the role of the international consortium on landslides (ICL). In: Sassa, K et al. (eds.), Advancing Culture of Living with Landslides, pp.109-115

USGS (2004) Landslides types and processes. 4 p. URL: https://pubs.usgs.gov/fs/2004/3072/pdf/fs2004-3072.pdf

Van Westen, CJ, Seijmonsbergen, AC and Mantovani, F (1999) Comparing landslide hazard maps. Natural hazards: J. of the Intern. Soc. for the Prev. and Mitig. of Nat. Hazards., 20:2-3, 137-158.

Varnes, DJ (1958) Landslide types and processes. In Landslide and Engineering Practice, Special Report 29, Highway Research Board, National Academy of Sciences, pp. 20-47.

Varnes, DJ (1978) Slope Movement types and processes. Landslide: Analysis and Control. Special Report 176, Transportation Research Board, National Academy of Sciences, pp. 20-47

Varnes, DJ (1984) Landslide Hazard Zonation-A Review of Principles and Practice. IAEG - United Nations Scientific and Cultural Organization, Commission on Landslides, pp. 1-6.

Wang, L, and Qu, J. (2007) NMDI: A normalized multi-band drought index for monitoring soil and vegetation moisture with satellite remote sensing. Geophys. Res. Lett., 34, L20405.

Wang, H and Sassa, K (2005) Comparative evaluation of landslide susceptibility in Minamata area, Japan. Environ Geol., 47:956-966.

Wokwenmendam Nguet, P (2019) Petrography, geochemistry and geochronology of Nana complex (Tikar plain): geodynamic and metallogenic implications. Translated from French original version. PhD dissertation, Earth Sciences department, university of Yaoundé, Cameroon, 243p.

World Landslide Forum-WLF (2017) Advancing culture of living with landslides, pp. 109-115.

Wu, Y, Li, W, Liu, P, Bai, H, Wang, Q, He, J, Liu, Y, and Suns (2016) Application of analytic hierarchy process model for landslide susceptibility mapping in the Gangu country, Gangu province. Environ Earth Sci, 75:422.

Xiao, T, Segoni, S, Chen, L, Yin, K, Casagli, N, (2020) A step beyond landslide susceptibility maps: A simple method to investigate and explain the different outcomes obtained by different approaches. Landslides 2020, 17, 627-640. 
Xiong, K, Adhikari, BR, Stamatopoulos, CA, Zhan, Y, Wu, S, Dong, Z, and Di, B (2020) Comparison of Different Machine Learning Methods for Debris Flow Susceptibility Mapping: A Case Study in the Sichuan Province, China. Remote Sens., 12:295.

Zhao, C and Lu, Z (2018) Remote sensing of landslides - A review. Remote Sens., 10:2, 279. 
Appendix 1. Landsat 8 scenes information (https://earthexplorer.usgs.gov)

\begin{tabular}{|l|l|l|l|}
\hline Year & Months & IDs & Center time \\
\hline \multirow{2}{*}{2014} & March & "LC81860562014080LGN01" & $09: 32: 50$ \\
\cline { 2 - 4 } & December & "LC81860562014352LGN01" & $09: 32: 33$ \\
\hline \multirow{2}{*}{2015} & January & "LC81860562015019LGN01" & $09: 32: 25$ \\
\cline { 2 - 4 } & December & "LC81860562015355LGN01" & $09: 32: 34$ \\
\hline \multirow{2}{*}{2016} & January & "LC81860562016006LGN02" & $09: 32: 30$ \\
\cline { 2 - 4 } & December & "LC81860562016358LGN03" & $09: 32: 40$ \\
\cline { 2 - 4 } & February & "LC81860562017056LGN00" & $09: 32: 19$ \\
\hline \multirow{2}{*}{2018} & December & "LC81860562017360LGN00" & $09: 32: 37$ \\
\cline { 2 - 4 } & Danuary & "LC81860562018027LGN00" & $09: 32: 22$ \\
\hline \multirow{3}{*}{2019} & January & "LC81860562019014LGN00" & $09: 32: 16$ \\
\cline { 2 - 4 } & June & "LC81860562019174LGN00" & $09: 32: 18$ \\
\cline { 2 - 4 } & December & "LC81860562019350LGN00" & $09: 32: 43$ \\
\hline
\end{tabular}

Appendix 2. Image classification and NDVI computation for LULC extent assessment

Because all the cloud-free satellite images of the study area are only available for the dry season, there is a need of matching the land use land cover (LULC) areas with the rainy season when landslides always take place. Then, an image of the rainy season was used from 23 June 2019, and a cloud-free subset was extracted on the natural land covers area, i.e., vegetation and soil, and a supervised classification was performed for each image. Their average overall accuracy is $92 \%$ and the average kappa coefficient is 0.89 . An image difference was then performed with the newest image (dry season) classification of the same year. The transformational technique that produces a change image from which a change/no change threshold must be established was used. It is expressed as a symmetric relative difference in the following equation: (Erdas, 2008)

$$
\mathrm{Va}=\frac{T_{2}-T_{1}}{\left|T_{1}\right|}+\frac{T_{2}-T_{1}}{\left|T_{2}\right|}
$$

Where $\mathbf{V a}$ is the new vegetation area and $\boldsymbol{T}$ is the time season image. It was noticed that in June, the 337845 hectares of the classification subset were occupied by the vegetation up to $61 \%$ (205,295 ha) versus $39 \%$ (132,550 ha) for soils, while in December, these percentages switch to 46\% (155,260 ha) for vegetation and 54\% (182587 ha) for soils. To confirm the objects extraction and the trends above, the Normalized Difference Vegetation Index (NDVI) was computed for the two images (Fig.15). 


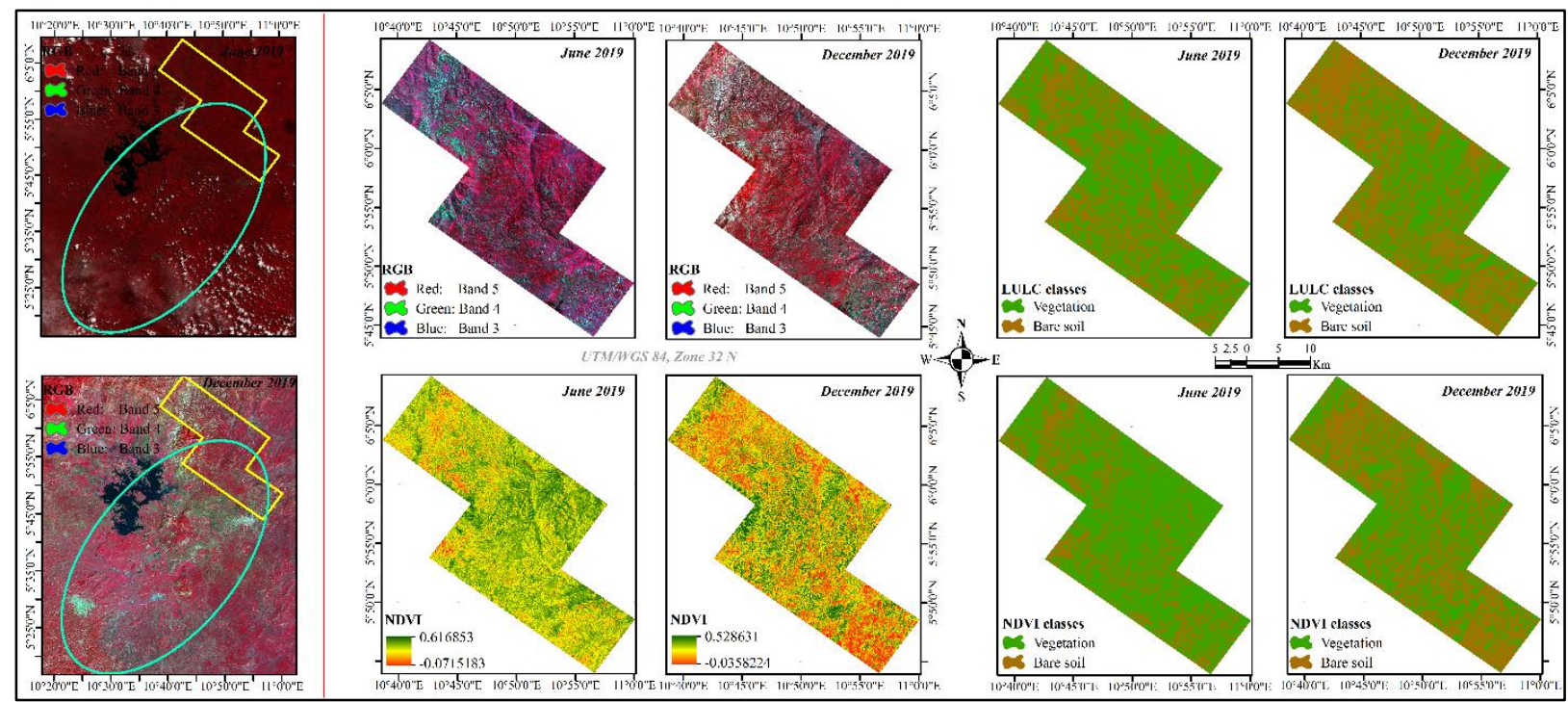

Figure 15. Subsets of land cover extent approximation

Statistics give $69 \%$ (233,113 ha) for vegetation and 31\% (104,732 ha) for soil in June, versus $47 \%$ (158,787 ha) for vegetation and 53\% (179,058 ha) for soil in December (Fig.14). The average percentages are $65 \%$ for vegetation and $35 \%$ for soils in June, versus $46.5 \%$ for vegetation and $53.5 \%$ for soils in December. The ratios of the rainy season over the dry season areas were computed, showing that the rainy season vegetation area is about 1.4 times bigger than in dry season. Assuming that the average percentages could have the same influence on the classification process, the ratio of vegetation extent (65\%) over the classification accuracy (92\%) was calculated. The result obtained, i.e., $0.598 \approx 0.6$, was summed with the previous value, 1.4 , as the best vegetation extent approximation for the rainy season, i.e., 2 times the vegetation area of the dry season's area. The ArcGISPro software expand function tool is useful for this purpose. In its principle, the class value targeted is multiplied by an $x$ factor ( 2 here) to approximate the area as needed. The algorithm is written as follows:

\section{Out_raster $=$ Expand $($ in_raster, number_cells, zone_values $)$}

With in_raster representing the reclassified raster image, number_cells being the $x$ factor and zone_values standing for the class to be expanded.

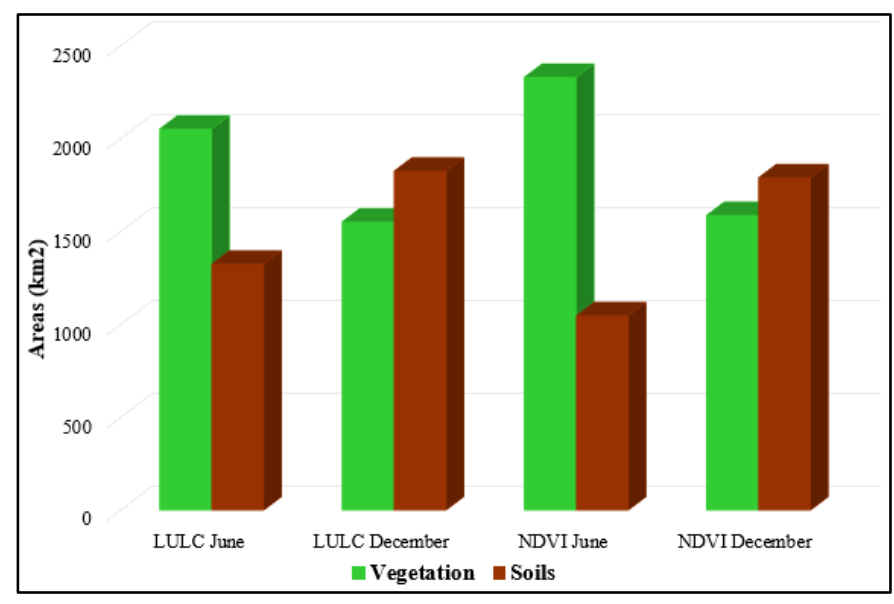

Figure 15. Land Use Land Cover (LULC) - comparison for the classification and the NDVI 
Appendix 3. Regression of MNMDI and Hydrothermal principal components bands
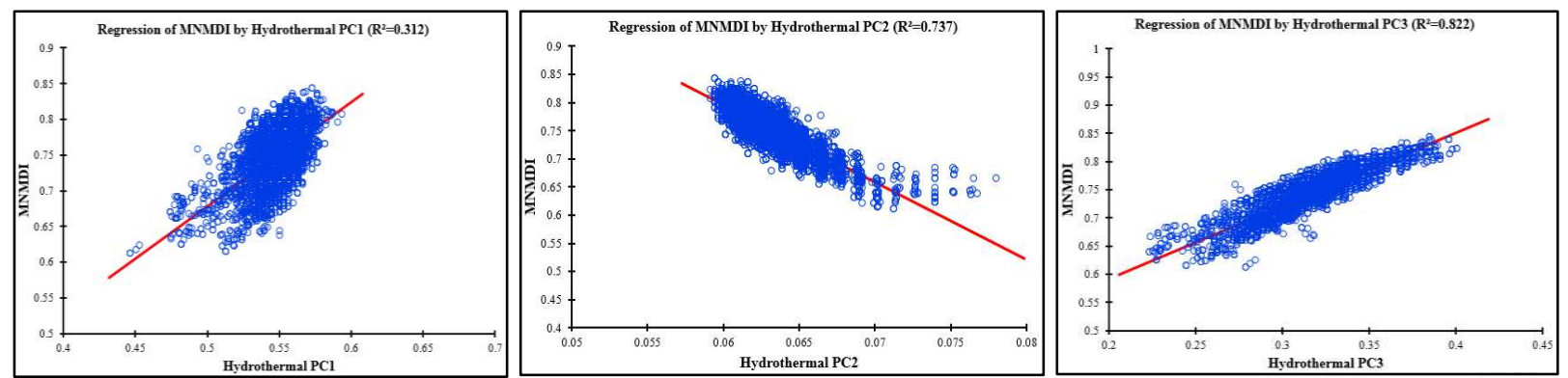

Appendix 4. Rainfall data for 1948-2018 (Orange) and 2019 (Green)

\begin{tabular}{|c|c|c|c|c|c|c|c|c|c|c|c|c|c|c|c|c|c|c|c|c|}
\hline & \multicolumn{2}{|c|}{ Zone 1} & \multicolumn{2}{|c|}{ Zone 2} & \multicolumn{2}{|c|}{ Zone 3} & \multicolumn{2}{|c|}{ Zone 4} & \multicolumn{2}{|c|}{ Zone 5} & \multicolumn{2}{|c|}{ Zone 6} & \multicolumn{2}{|c|}{ Zone 7} & \multicolumn{2}{|c|}{ Zone 8} & \multicolumn{2}{|c|}{ Zone 9} & \multicolumn{2}{|c|}{ Zone 10} \\
\hline & $\bar{R}$ & $D$ & $R$ & $D$ & $R$ & $D$ & 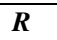 & $D$ & $R$ & $D$ & $R$ & $D$ & $R$ & $D$ & $R$ & $D$ & $R$ & $D$ & $R$ & $D$ \\
\hline Jun. & 350 & 27 & 350 & 25 & 352 & 28 & 352 & 25 & 369 & 25 & 361 & 25 & 377 & 25 & 389 & 24 & 358 & 24 & 369 & 25 \\
\hline Jul. & 550 & 24 & 555 & 26 & 554 & 24 & 577 & 24 & 609 & 26 & 587 & 25 & 618 & 27 & 573 & 26 & 590 & 25 & 612 & 25 \\
\hline Aug. & 617 & 25 & 620 & 25 & 648 & 25 & 650 & 26 & 654 & 28 & 658 & 28 & 688 & 29 & 687 & 31 & 679 & 30 & 692 & 27 \\
\hline Sept. & 592 & 28 & 600 & 28 & 590 & 26 & 611 & 28 & 625 & 28 & 600 & 28 & 589 & 29 & 644 & 29 & 666 & 30 & 617 & 30 \\
\hline Oct. & 378 & 26 & 377 & 26 & 392 & 23 & 379 & 25 & 391 & 24 & 398 & 24 & 395 & 23 & 412 & 23 & 445 & 25 & 400 & 24 \\
\hline Jun & 363 & 24 & 360 & 24 & 355 & 24 & 360 & 26 & 355 & 24 & 358 & 25 & 377 & 25 & 374 & 25 & 370 & 24 & 370 & 24 \\
\hline Jul. & 546 & 25 & 583 & 25 & 535 & 24 & 579 & 24 & 579 & 26 & 600 & 26 & 557 & 27 & 548 & 28 & 571 & 25 & 577 & 25 \\
\hline Aug. & 613 & 28 & 615 & 28 & 630 & 28 & 642 & 28 & 637 & 29 & 641 & 29 & 688 & 30 & 669 & 30 & 643 & 29 & 690 & 29 \\
\hline Sept. & 597 & 30 & 580 & 28 & 581 & 28 & 594 & 28 & 618 & 30 & 617 & 30 & 615 & 29 & 644 & 29 & 621 & 30 & 633 & 29 \\
\hline Oct. & 372 & 24 & 379 & 20 & 381 & 20 & 377 & 19 & 374 & 19 & 377 & 20 & 395 & 20 & 393 & 21 & 392 & 21 & 404 & 24 \\
\hline
\end{tabular}

$R=$ rainfall in millimeters and $D=$ rainy days. 
Figures
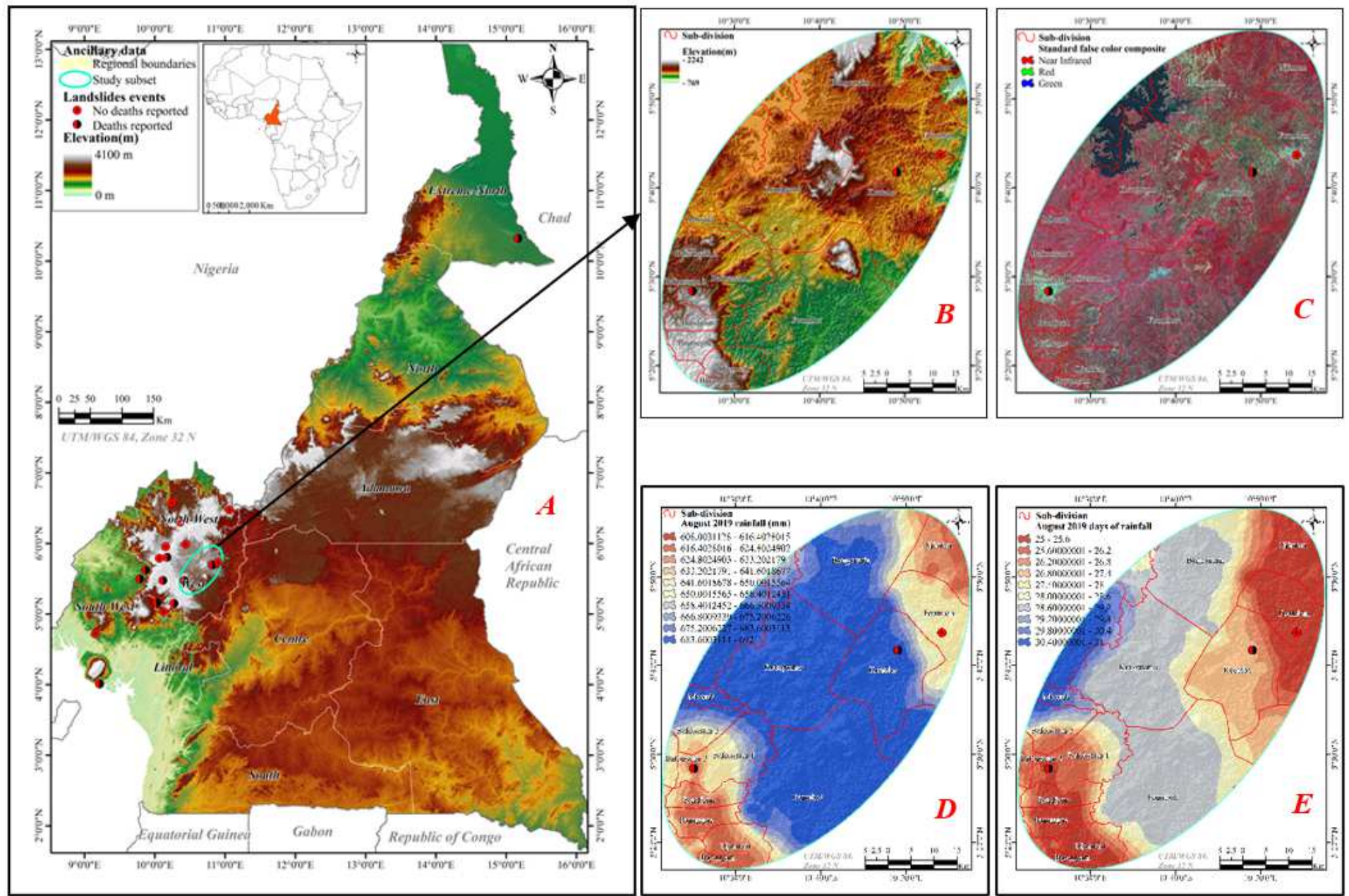

Figure 1

The study location. A) Country elevation and landslides events. B) \& C) - Subset of study elevation and Landsat OLI-TIRS image. D) Interpolated average rainfall for August. E) Interpolated days of rainfall for August
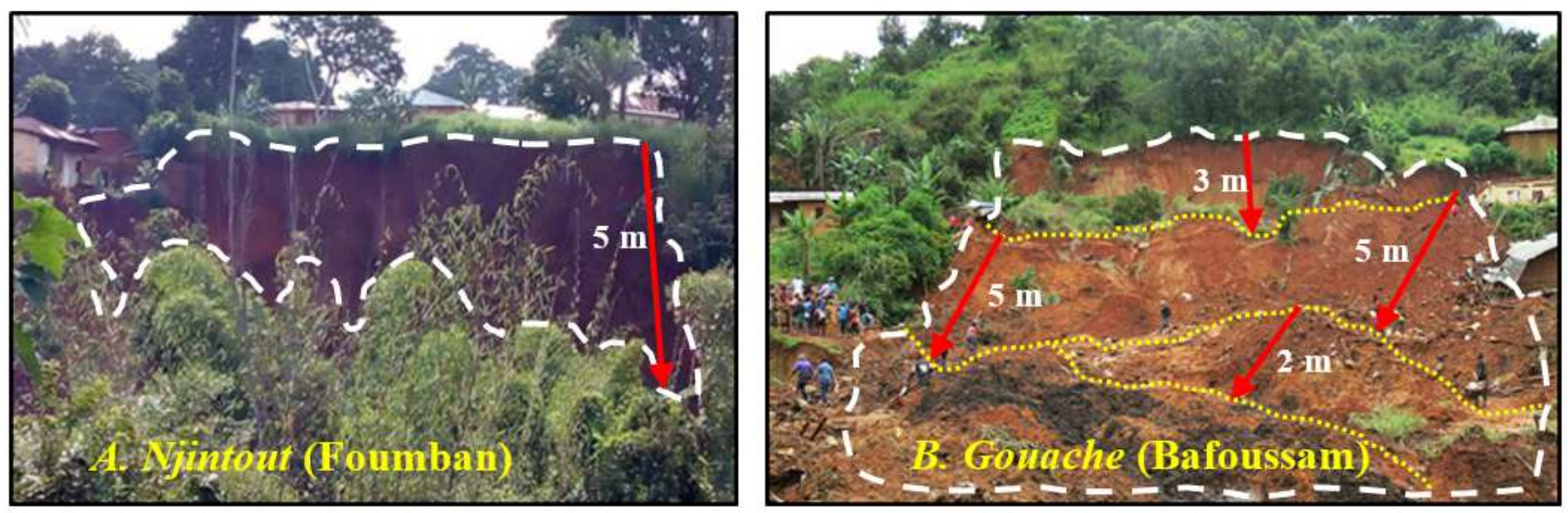
Figure 2

Unscaled partial views of the scarps leaved by landslides of Foumban (2018) and Bafoussam (2019). Both events were sudden with transitional to rotational movements, but the one in Foumban happened in one step, while the one in Bafoussam happened in three steps (yellow dashed), justifying three main blocks/stairs. Base on the soil horizontal surface, the sliding depths (arrows) are 5 meters in Foumban, and 1 to 5 meters in Bafoussam. The affected area was $\approx 30,100 \mathrm{~m} 2$ in Foumban (IGMR-Penaye et al., 2018) and $\approx 15,051 \mathrm{~m} 2$ in Bafoussam. (IGMR-Kankeu \& Ntchantcho, 2019)

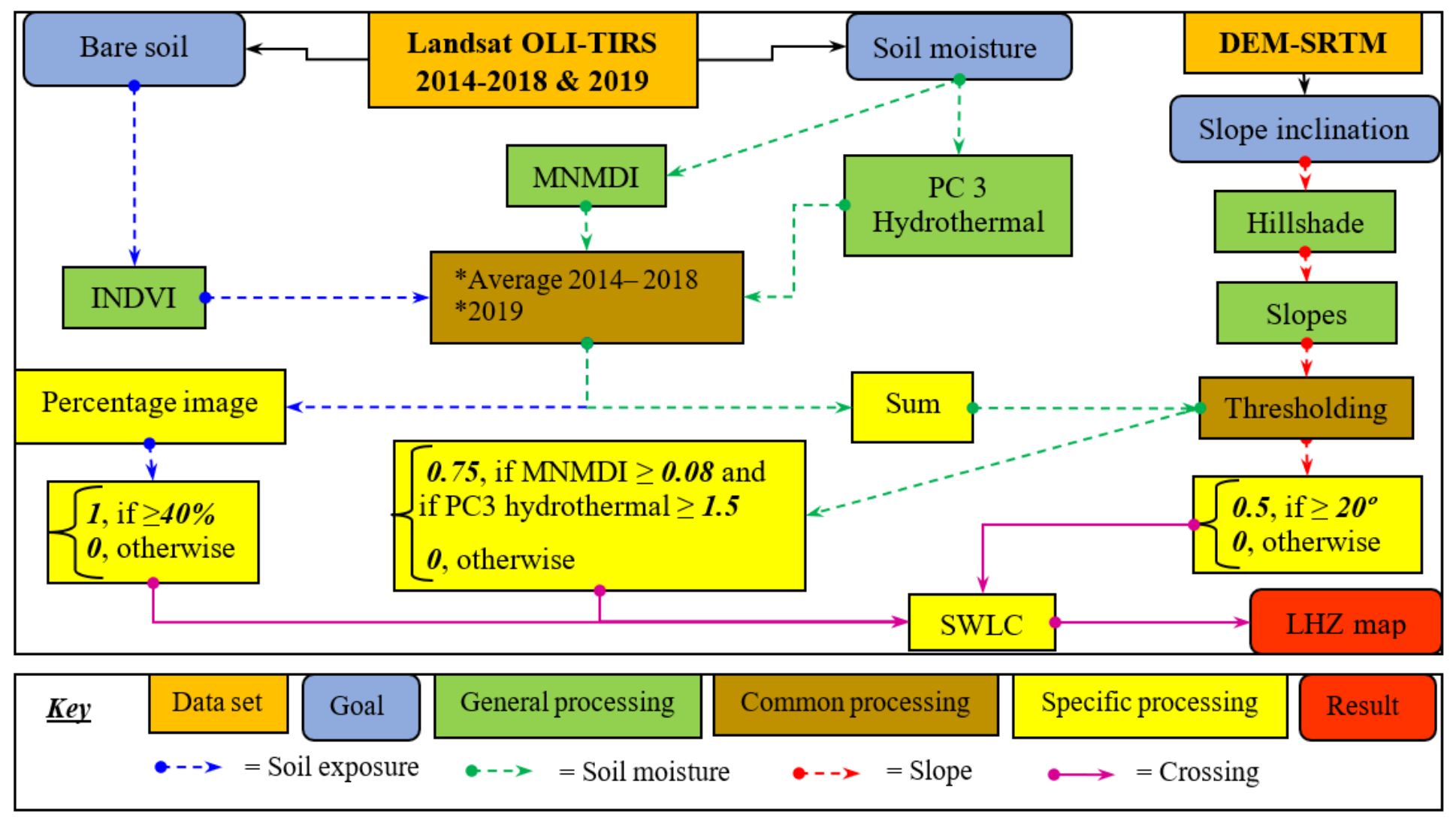

Figure 3

Workflow of the SLIP process 


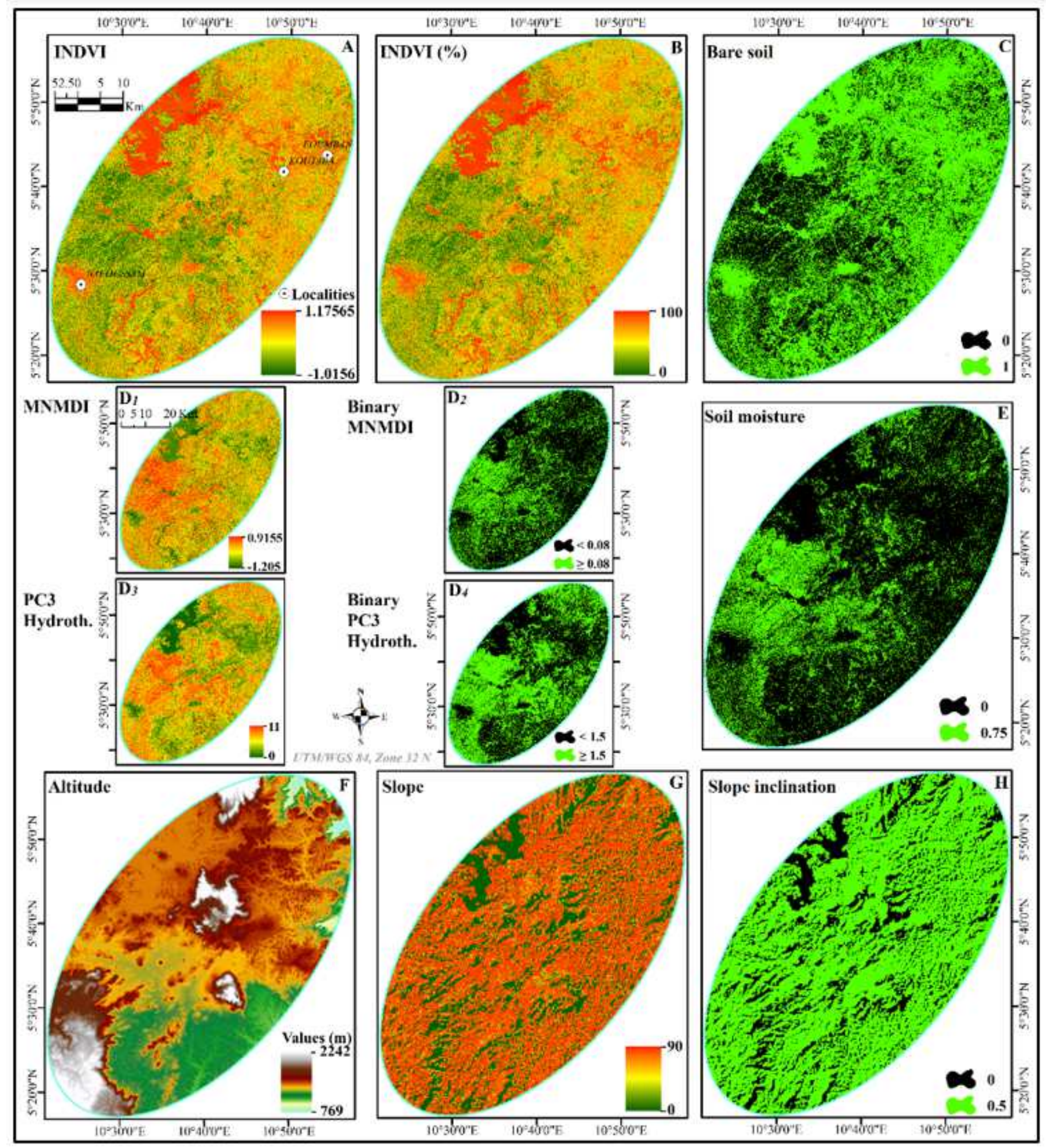

Figure 4

SLIP stretched and conditioned layers 

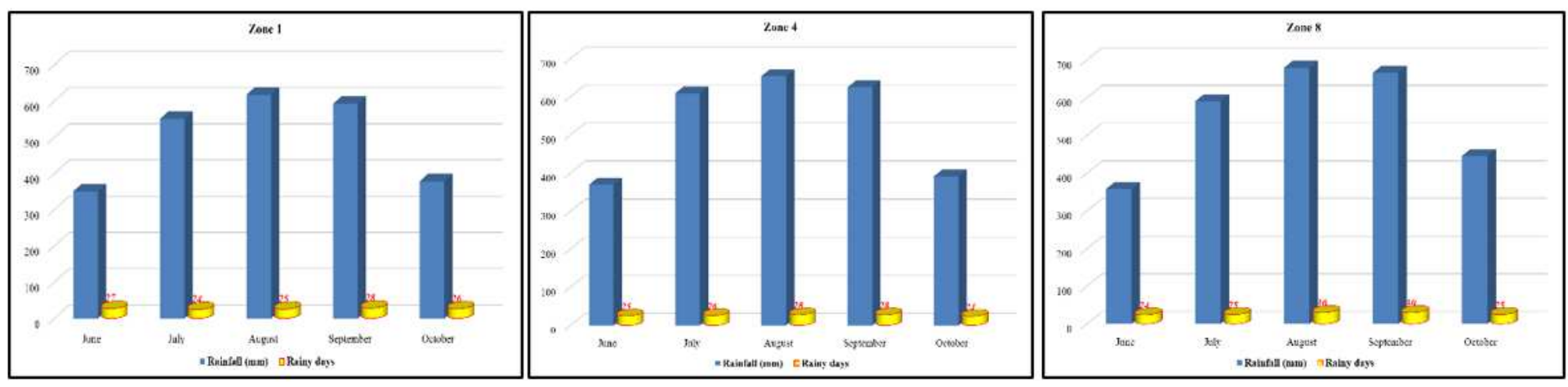

Figure 5

Monthly rainfall and rainy days sampled for three zones of the study area in 2019
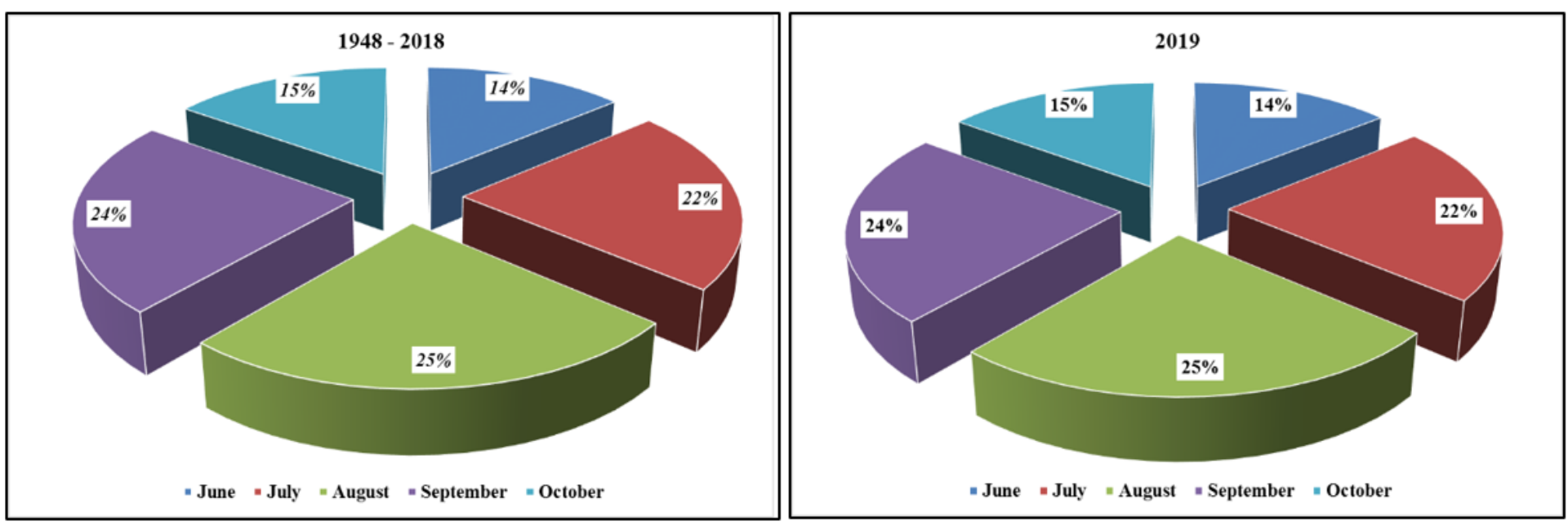

Figure 6

Percentage of monthly rainfall between June and October
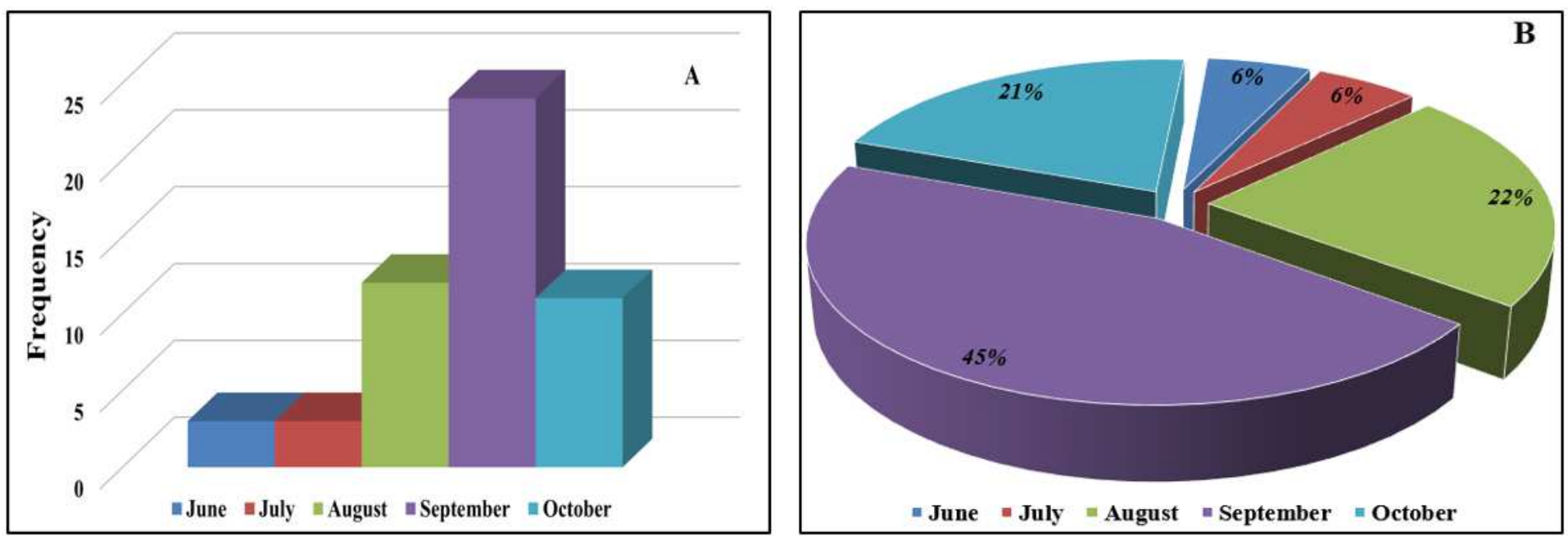

Figure 7

Monthly frequency (A) and percentage (B) of landslides between 1954 and 2019 

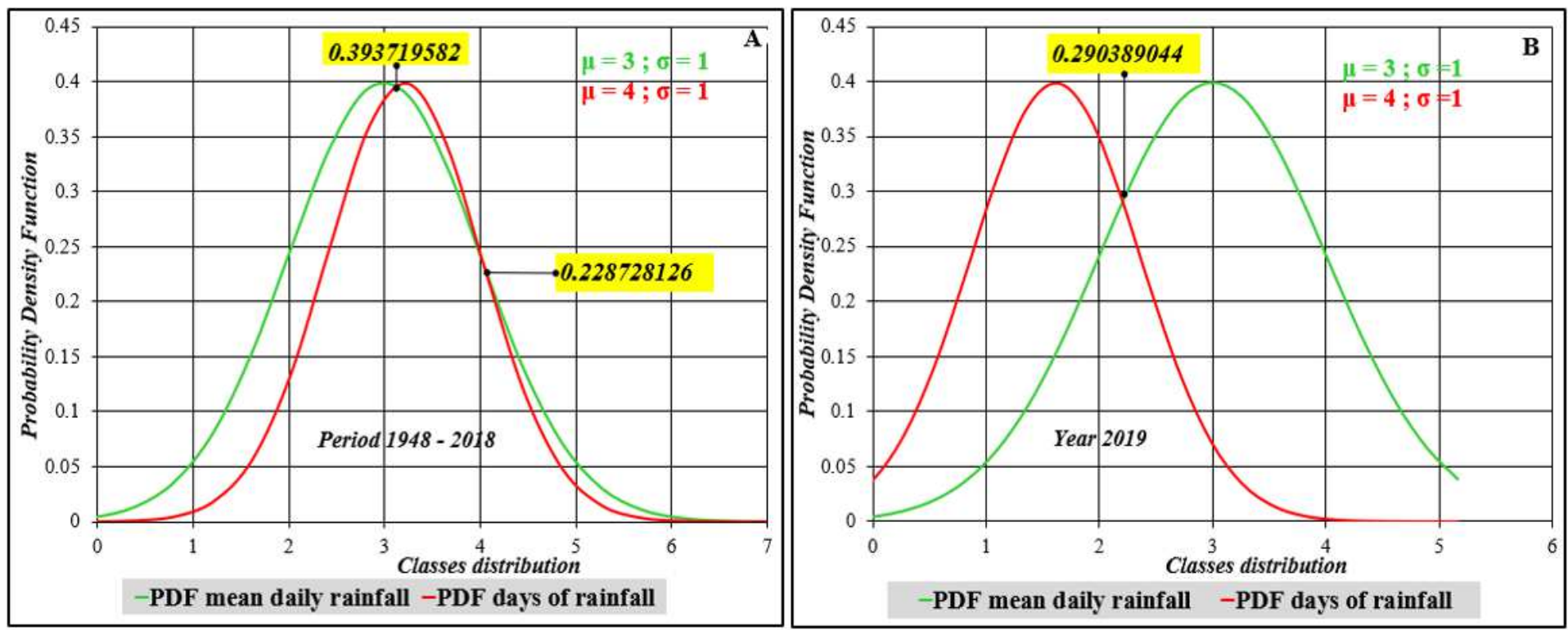

\section{Figure 8}

Individual PDF curves and their intersections before (A) and in (B) 2019

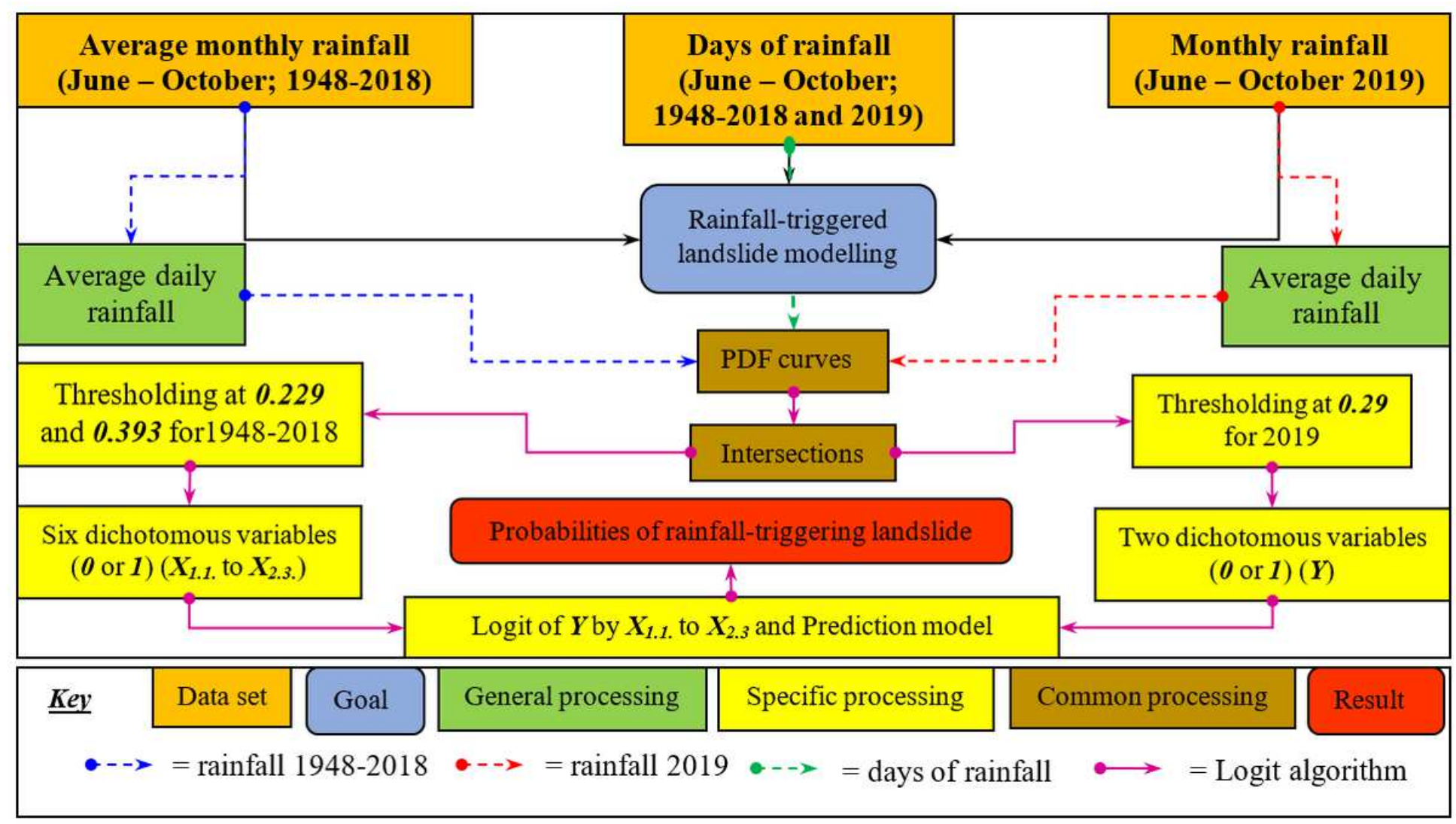

\section{Figure 9}

Workflow of the DRIP process 


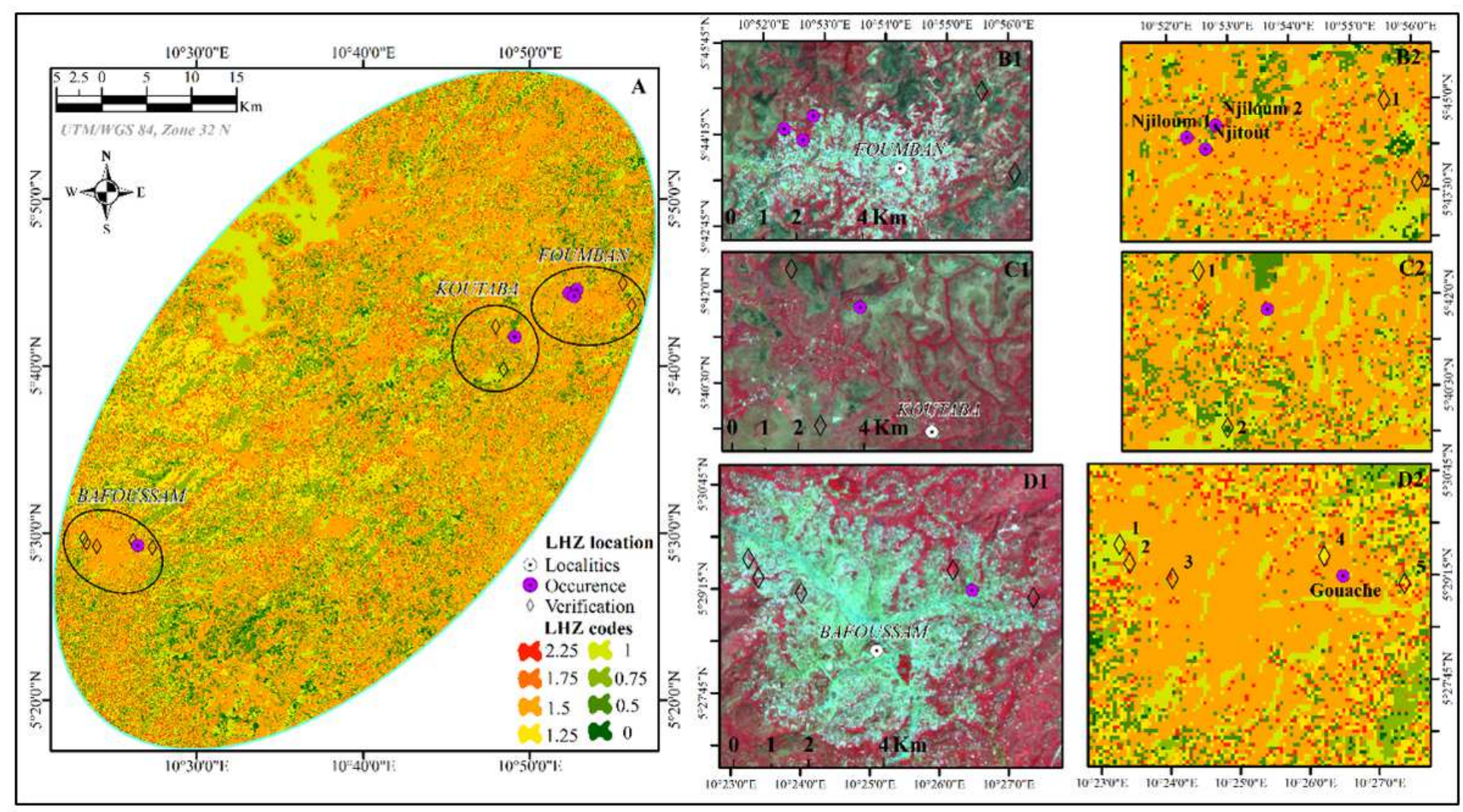

Figure 10

LHZ mapping. A) The eight classes of landslide occurrence extent and corresponding codes. B1) and B2) Patterns and sites location in Foumban. C1) and C2) Patterns and sites location in Koutaba. D1) and D2) Patterns and sites location in Bafoussam.
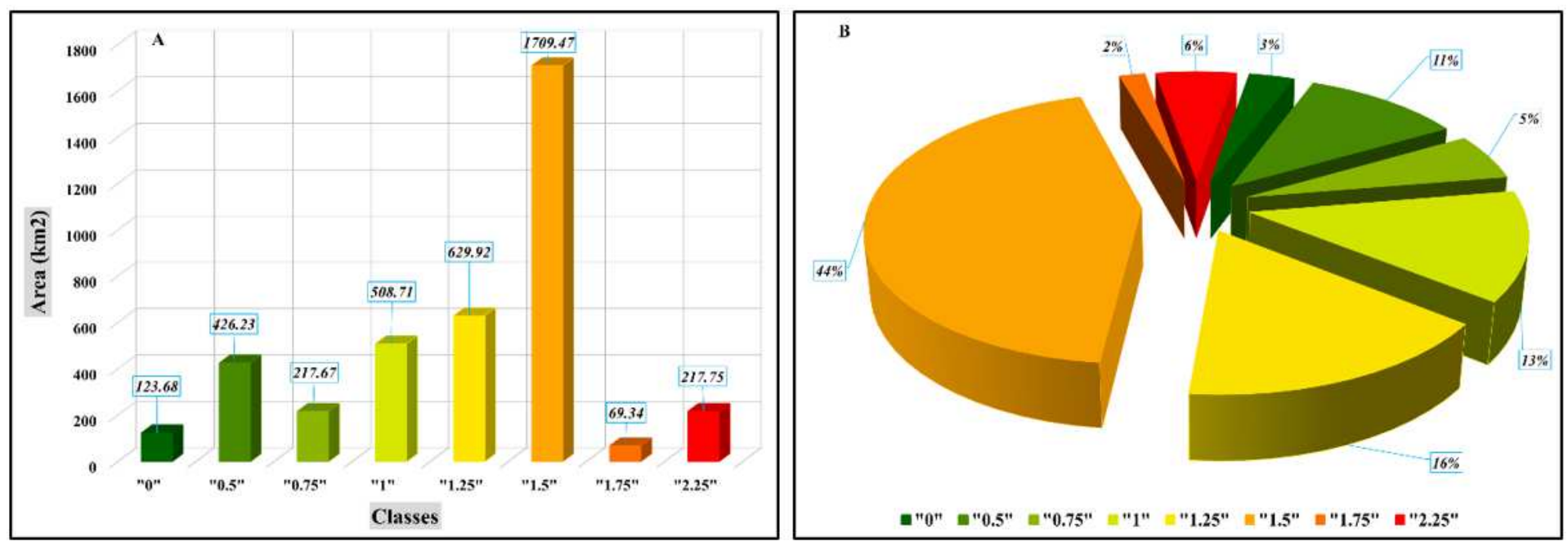

Figure 11

Areas $(A)$ and percentages $(B)$ of $L H Z$ per classes 

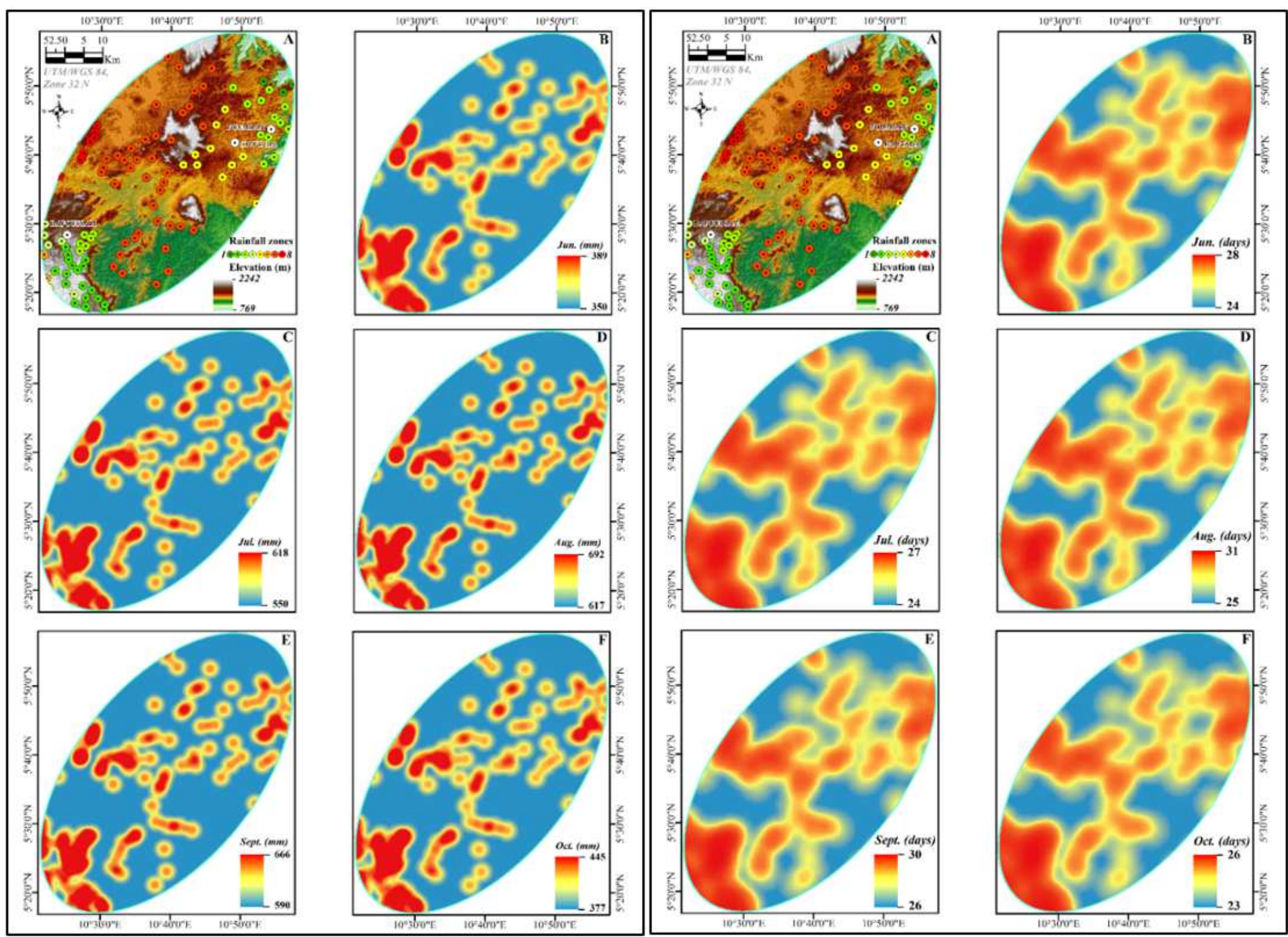

\section{Figure 12}

Spatial distribution of daily rainfall (left) and days of rainfall (right) from June to October
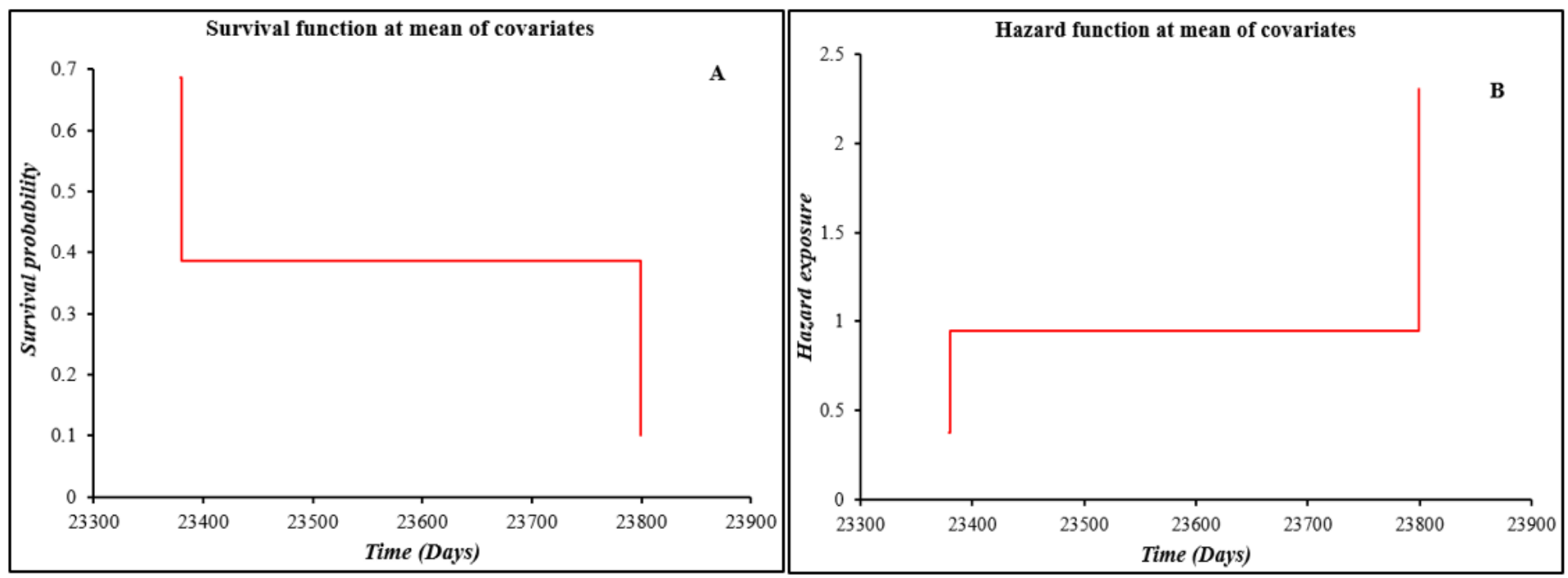

Figure 13 
Survival probability (A) and hazard exposure (B) of the five landslide occurrence sites 